\title{
RELATIONSHIP BETWEEN MOTIVATIONAL CLMATE TO BODY ESTEEM AND SOCIAL PHYSICAL ANXIETY WITHIN COLLEGE PHYSICAL ACTIVITY CLASSES
} By

Sheryl M. Miller

Submitted to the graduate degree program in Health, Sport and Exercise Science and the Graduate Faculty of the University of Kansas in partial fulfillment of the requirements for the degree of Master of Science.

Chairperson, Mary D. Fry

\begin{tabular}{c}
\hline Theresa C. Brown \\
\hline Amber J. Long \\
\hline Andrew C. Fry
\end{tabular}

Date Defended: May 9, 2015 
The Thesis Committee for Sheryl M. Miller

certifies that this is the approved version of the following dissertation:

RELATIONSHIP BETWEEN MOTIVATIONAL CLMATE TO BODY ESTEEM AND SOCIAL PHYSICAL ANXIETY WITHIN COLLEGE PHYSICAL ACTIVITY CLASSES

Chairperson, Mary D. Fry

Date approved: May 27, 2015 


\begin{abstract}
College is a time for many young adults to establish habits that support a healthy lifestyle, but research suggests most college students give low priority to health habits (Nelson, Kocos, Lytle, \& Perry, 2009). Physical activity has numerous benefits, including improved body esteem, if engaging in physical activity for health-related reasons rather than appearance-related reasons (Davis, 2002). College is often marked by decreased BE (Keating, et. al., 2005), hence, fitness professionals need to understand how to foster college students' engagement in regular physical activity that simultaneously encourages positive BE. Achievement goal perspective theory and a caring framework have both been successful in optimizing all individuals' motivation in the exercise setting (Brown \& Fry 2013). Therefore, the purpose of this study was to examine the effect of individuals' perceptions of the motivational climate across a semester long exercise class to their BE (i.e., appearance and weight) and social physique anxiety (SPA) within the class. It was hypothesized that students who experience a caring and task-involving climate in their classes would report heightened BE and lower SPA. Students enrolled in physical activity classes at a large Midwestern university completed a survey that measured their BE, SPA, and perceptions of motivational climate. Canonical correlation analysis loadings revealed that students' perceptions of a highly caring and task-involving climate with low emphasis on egoinvolving climate features were associated with their reporting higher body and appearance esteem and lower SPA. More research is needed to examine the link between motivational climate and BE, mounting evidence shows the support of creating positive and supportive exercise environments.
\end{abstract}




\section{Acknowledgments}

There are many people to thank and acknowledge for their contributions to this project. To my helpers, without you, the data would have never been collected; thus, this work would be nonexistent. You sacrificed your time to help me, and I am grateful for each of your contributions. Allie, Ashley, Brian, Clarice, Emily, Nick, Nii, Nik, Mook, Steph, Taylor, and Zach, you should be proud of your efforts. I am!

My sport and exercise psychology lab mates must also be acknowledged in both helping me collect data and teaching me directly and indirectly about this wonderful field of study. Aly, Ashley, Candace, Cody, Daniel, Emily, Joe, Kiira, Kyle, Lauren, Mario, Mike, Ruben, Susumu, and Taylor-I am very honored I had the opportunity to work with you during my time at the University of Kansas.

Statistics is not my strong suit, so I am incredibly appreciative of all the help from Susumu Iwasaki and Emily Kramer. Thank you for taking time away from your own busy schedules to work with my data. Susumu had his own doctoral work and Emily had a full-time job and family, yet both spent hours working with me. Thank you very much.

My family has shaped me into who I am today and provide me with the motivation to keep giving my greatest effort in every endeavor. Throughout this journey of research and writing, each one of them has taught me life lessons that assisted me as I completed my thesis. My sister Sara taught me all dreams are possible, if only we believe in our ability. My brother Marvin taught me the power of perseverance and never giving up no matter what the perceived roadblock. My dad taught me how to keep moving forward despite stress through his sense of humor and constant support. My mom taught me the virtues of a strong work ethic and compassion to each and every human being. Though not family, my good friend Josh must be 
acknowledged for bearing the brunt of my stress-induced behaviors experienced throughout this process. No matter what emotion I experienced — joy, anguish, irritability—-he was always there with words of encouragement and support sans judgement. I truly am a better person (e.g., researcher, friend) with him in my life. My love and appreciation for my mom, dad, Sara, Marvin and Josh is ineffable.

Throughout my work, I have been exceedingly fortunate to have such amazing mentors and role models. These amazing people deserve much more recognition, and I am deeply honored that they were also on my committee. Andy, thank you for your interesting discussion points during my thesis defense. I appreciate you taking time out of your schedule to sit on my committee and offer feedback from an exercise physiology standpoint.

Theresa, you were the first person to introduce me to this research while I was an undergraduate. You provided me opportunities and hands-on learning (e.g., Strong Girls, your own data collection, preparation for the CHES) that allowed me to flourish in graduate school as well as life. I appreciate your positivity no matter the situation. Thank you for your guidance.

Amber, you were the first person to show me the benefits of creating positive and supportive physical activity environments - even before I delved into the theories. From your guidance and mentoring, I have learned the skills needed to transverse the fitness world and ultimately continue my career in the field of exercise psychology. Thank you for your leadership.

Mary, you are one of the most caring and positive teachers I have had the privilege of knowing. You do not simply teach the material, you live it every single day. I have learned more from watching you employ each theory's tenets than I ever could from reading an article. The countless hours you have spent helping me with research, writing, and schoolwork is invaluable. Yet, you always allowed me to uncover the information myself. Thank you. Your work (as a 
mother, daughter, friend, colleague, leader, mentor, wife, teacher, and professional) is astounding. I cherish the fact you were my advisor.

Mary, Theresa, and Amber, you are all phenomenal teachers, mentors, and friends. I value each and every piece of feedback given to me. I am amazed that I have had the chance to personally work with each of you. Very few people have one or two great mentors in their lifetimes, and I am lucky enough to say I have already had three. Thank you for all of your support, guidance, and motivation. You each embody this work fully and have helped prepare me to do the same. I am forever indebted to you.

To all researchers, especially in the fields represented in this document, thank you for spending the time and effort to try and make this world better through scientific evidence.

Without your prior contributions, my life would be less meaningful. I appreciate your dedication. 


\section{Table of Contents}

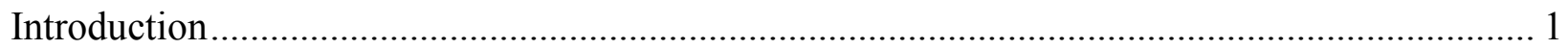

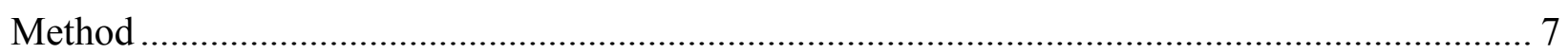

Procedure and Participants.......................................................................................... 7

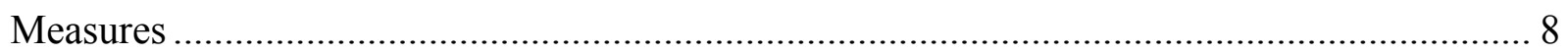

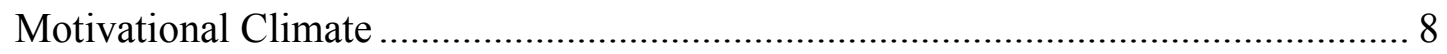

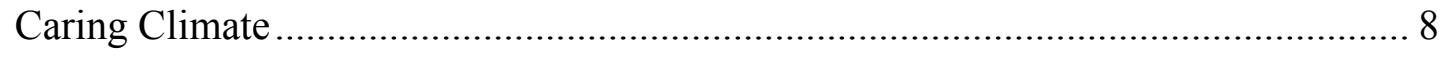

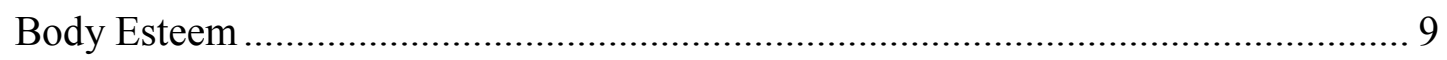

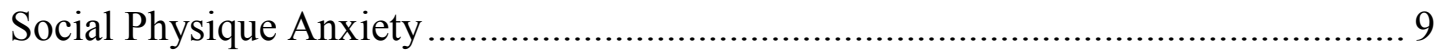

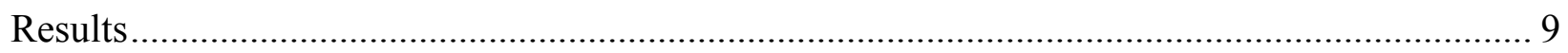

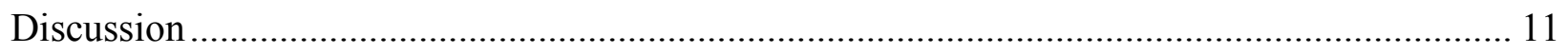

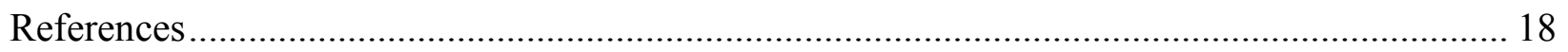

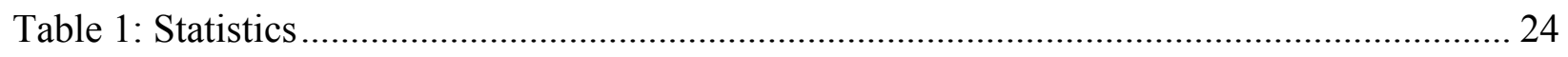

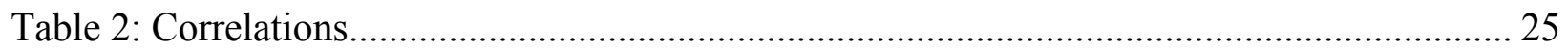

Figure 1: Total Sample Canonical Correlation Analysis .................................................. 26

Figure 2: Female Canonical Correlation Analysis ............................................................... 27

Figure 3: Male Canonical Correlation Analysis ............................................................... 28

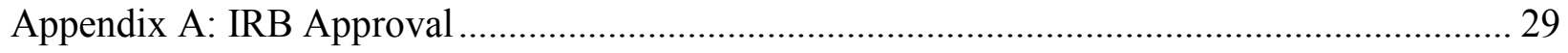

Appendix B: Extended Literature Review .............................................................. 31

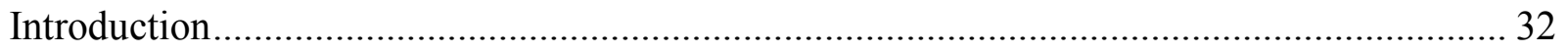

Achievement Goal Perspective Theory ….................................................................. 32

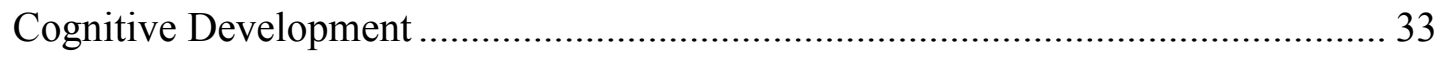

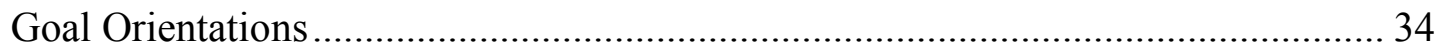


Motivational Climates................................................................................. 35

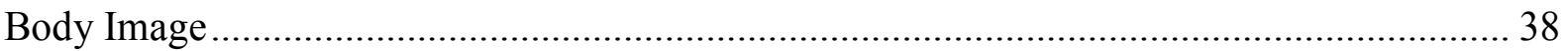

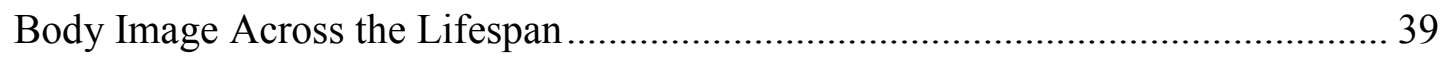

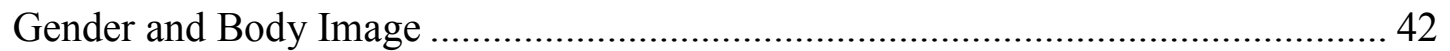

Other Influences on Body Image Development............................................... 42

Physical Activity, Social Physique Anxiety, and Body Image .............................. 44

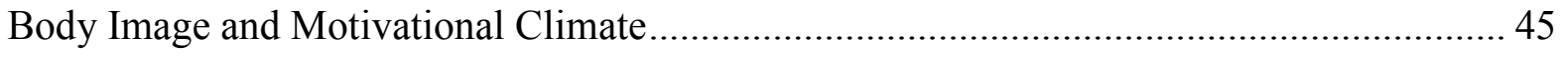

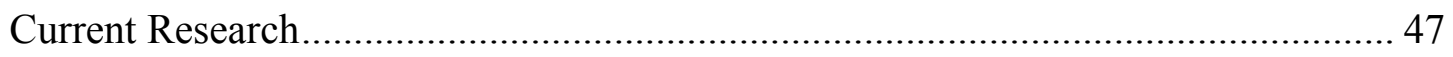

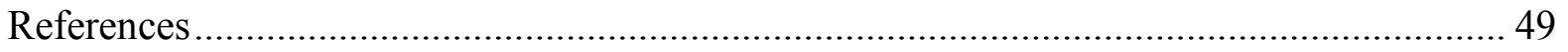

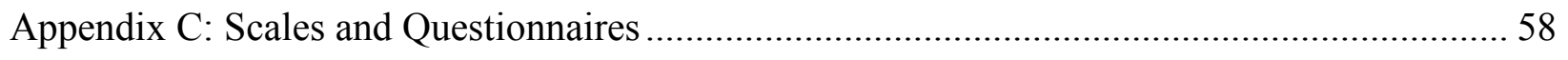




\section{Introduction}

College is a time for many young adults to establish habits that support a healthy lifestyle, but research suggests most college students give low priority to health habits (Nelson, Kocos, Lytle, \& Perry, 2009). Faced with new lifestyle choices, social networking demands, and numerous deadlines, this stress can manifest itself in students' decision to exclude physical activity from their busy schedules. Research has revealed that $30 \%$ to $50 \%$ of the college population does not engage in adequate exercise to warrant health benefits (Keating, Guan, Piñero, \& Bridges, 2005). Given the positive association between individuals' physical activity levels in college and the maintenance of physical activity later in life (Kulavic, Hultquist, \& McLester 2013; Keating, et. al., 2005), health professionals have much to gain from understanding how to maximize college students' experiences in physical activity. Physical activity has numerous benefits, including improved body esteem (BE), if engaging in physical activity for health-related reasons rather than appearance-related reasons (Davis, 2002). Body esteem is a global construct associated with self-worth and has been positively associated with interpersonal confidence, appropriate eating and exercise behaviors, and emotional stability (Mendelson, Mendelson, \& White, 2001; Cash, Melnyk, \& Hrabosky, 2004). However, of the college students that engage in physical activity, many do so for appearance-related reasons, (Brudzynski \& Ebben, 2010; Kulavic, et.al., 2013), which may contribute to the already decreased BE many college goers experience (Paap \& Gardner, 2011). Therefore, fitness professionals would benefit from better understanding how to foster college students' engagement in regular physical activity that simultaneously encourages positive BE.

Achievement goal perspective theory (AGPT; Nicholls, 1989; Roberts, 2012) is one framework that has been employed in exercise psychology research to consider how to optimize 
individuals' motivation in physical activity settings. Two distinct motivational climates can be created by instructors in achievement settings. In an ego-involving climate, instructors perceive that promoting competition and employing normative standards of performance to define individuals' ability will enhance motivation (Nicholls, 1984, 1989). Strategies that reinforce this climate include fostering rivalry among individuals, only recognizing the top performers in the setting, and punishing mistakes made by participants. Fitness professionals that create a strong ego-involving climate send the message that success is achieved by outperforming others.

The antithesis to an ego-involving climate is the task-involving climate, where the focus is on individuals' effort and improvement. Instructors who foster a task-involving climate emphasize personal mastery of skills (as opposed to normative comparisons), foster cooperation among participants, and advocate that mistakes are part of the learning process (Nicholls, 1989). Success is measured by an individual's personal effort and improvement over time. Research has consistently revealed the benefits of creating a highly task-involving climate, as well as the problematic outcomes associated with an ego-involving climate (Harwood, Keegan, Smith, \& Raine, in press).

In addition to the importance of creating a task-involving climate, recent research has also highlighted the value of fostering a caring climate, where individuals feel safe, welcomed, respected, and supported. Instructors create this climate by getting to know participants and learning information about their background, expressing sincere concern for participants, and being accepting of everyone involved (Fry \& Gano-Overway, 2010; Fry, Guivernau, Kim, Newton, Gano-Overway, \& Magyar, 2012; Newton, Watson, Gano-Overway, Fry, Kim, \& Magyar, 2007; Brown \& Fry, 2013). 
Research has consistently supported the theoretical tenets of AGPT and a caring framework, especially in an exercise setting. Perceptions of a caring and task-involving climate have been linked to many positive outcomes such as greater exercise adherence, increased effort, enjoyment, and self-confidence within an exercise setting. Moore and Fry (2014) surveyed college group exercise participants and found that their perceptions of a caring and taskinvolving climate were positively correlated to their sense of empowerment and ownership in exercise, whereas perceptions of an ego-involving climate were negatively correlated. Similarly, when Brown and Fry (2013) surveyed college females in a group exercise setting, they found that participants who perceived a caring and task-involving climate were more likely to report that they exercise for enjoyment, health, and fitness reasons than those perceiving an egoinvolving climate. Correspondingly, Hogue, Fry, Fry and Pressman (2013) manipulated a physical activity setting to be either caring and task-involving or ego-involving while participants were learning a new skill. Individuals in the ego-involving climate reported greater anxiety, self-consciousness, shame, and increased cortisol production during and after the session, whereas individuals in the caring and task-involving climate actually experienced a drop in cortisol production during and after the session. In addition, they reported greater enjoyment, effort, self-confidence, and interest in continuing the new skill. Research is clearly outlining the positive outcomes linked to creating a caring and task-involving climate in physical activity settings.

Another benefit of creating positive and supportive climates in exercise settings may be improved BE, which is the self-evaluation of one's body or appearance (Mendelson, et.al., 2001). Body esteem is a global construct that positively correlates to self-esteem (2001; Koff, Benavage, \& Wong, 2001) and can be affected by an individual's weight and appearance. 
Physical activity has been linked to greater BE if exercising for health-related reasons (Davis, 2002). However, physical activity for appearance-related reasons can decrease BE, despite consistent physical activity (Krane, Stiles-Shipley, Waldron, \& Michalenok, 2001; Hagger, Hein, \& Chatzisarantis, 2011; Hausenblas \& Fallon, 2006). This is especially true if exercisers experience social physique anxiety (SPA), the belief their bodies are being negatively evaluated by others around them, resulting in feelings of anxiety or apprehension (Hart, Leary, \& Rejeski, 1989).

In the sport and physical activity domains, there is sometimes an erroneous assumption that a thinner body results in better performance (Waldron \& Krane, 2005; Krane, Greenleaf, \& Snow 1997; Coppola, Ward, \& Freysinger, 2014). When this view is coupled with SPA, it can lead to either exercise avoidance or addiction, and other negative health behaviors (Krane, et.al., 2001; Martin Ginis \& Leary, 2004), as well as decreased BE. It is also well-documented that engaging in physical activity for appearance-related reasons results in less intrinsic motivation, less exercise adherence, and body dissatisfaction (Brown \& Fry, 2013, 2014; Hubbard, Gray, \& Parker, 1998; Tiggemann \& Williamson, 2000). A meta-analysis conducted by Keating, et. al. (2005) found that the college population, unfortunately, generally cites looking good as a primary reason for engaging in physical activity (p. 120). This suggests that a focus on appearance may be counterproductive when group fitness professionals are striving to increase individuals' engagement in exercise and prevent exercisers from experiencing anxiety or bodyevaluative threat.

Existing research suggests the social culture developed in group exercise settings is positively related to exercise adherence and commitment to future exercise (Fraser \& Spink, 2002; Brown \& Fry, 2013). This is especially true if participants within the setting perceive a 
positive and supportive climate (Brown \& Fry, 2013; Moore \& Fry, 2014). However, group exercise settings can also lead to direct and/or indirect comparisons among participants (Pila, Stamiris, Castonguay, \& Sabiston, 2014). Social comparisons often result in body image dissatisfaction, which can put individuals at risk of maladaptive health behaviors such as exercise addiction and/or disordered eating (Fitzsimmons-Craft, Harney, Brownstone, Higgins, \& Bardone-Cone, 2012; Krane, et.al., 2001). Therefore, creating positive and nurturing climates may minimize body comparisons among individuals and encourage exercise adherence.

In summary, BE dissatisfaction is often a result of individuals perceiving their bodies are being evaluated (Fitzsimmons-Craft, et.al., 2012), and an environment that features social comparison and competition would likely elicit BE dissatisfaction. An ego-involving climate promotes comparisons which can include the appearance and weight of individuals, and a caring and task-involving climate focuses on accepting all individuals and emphasizing personal effort. Therefore, an important area of inquiry involves examining the potential link between motivational climate to BE satisfaction.

Current research relating BE and AGPT is sparse. De Bruin, Bakker, \& Oudejans (2009) found that in a sport setting, both ego orientation and perceptions of an ego-involving climate were related to lower self-esteem and more dieting and weight-related peer pressure in gymnasts and dancers. Conversely, a task-involving climate was negatively related to disordered eating. Disordered eating, and eating disorders in general, are positively correlated with BE dissatisfaction (Henriques \& Calhoun, 1999), suggesting that AGPT may play a role in helping or hindering BE satisfaction. On a related note, González-Cutre and Sicilia (2012) found that exercise dependence is more likely to develop in an ego-involving climate, where comparisons between exercisers can lead to the desire to have a more "beautiful, sculpted, or in-shape body 
than others" (p. 325). This desire can be manifested in unhealthy exercise behaviors leading to unfortunate outcomes such as exercise dependence, an indicator of BE dissatisfaction (Garner, 2002).

Brown and Fry (2013, 2014; Huddleston, Fry, \& Brown, 2012) have also measured AGPT in the physical activity domain. Studying the motivational climates perceived in various fitness arenas (i.e., national fitness franchise, aerobics classes, college recreation center), they have found that those perceiving higher caring, task-involving climates report greater commitment to exercise, positive well-being, and health-related reasons for exercising, as opposed to appearance-related reasons, like obtaining greater muscle tone or physical attractiveness (2012). These findings do not include measures of BE, but lay the foundation to examine this link, particularly because there was a positive association between climate, wellbeing, and exercising for health-related, as opposed to appearance-related, reasons.

Stark and Newton (2014) recently found support for the link between climate to BE. Specifically, they reported that a caring, task-involving climate, or one that de-emphasized an ego-involving climate, was related to greater BE as well as positive overall well-being in recreational dancers. The cooperative nature and nurturing features of the caring, task-involving climate should result in greater acceptance and support, which likely leads individuals to feel less self-conscious about themselves and their appearance. Conversely, perceptions of an egoinvolving climate are likely to result in greater comparisons among participants, resulting in heightened self-consciousness about themselves and their appearance. To date, these findings have not been replicated, but likely would be in an exercise setting.

Clearly, research is needed to examine the connection between individuals' perceptions of their exercise climate to their BE. Because the college population is at an increased risk for 
both BE dissatisfaction and inadequate physical activity levels, the purpose of this study was to examine the effect of individuals' perceptions of the motivational climates in a semester long exercise class to their BE (i.e., appearance and weight) and SPA within the class. It was hypothesized that students who experience a caring and task-involving climate in their classes would report heightened BE and lower SPA. These relationships are hypothesized to be consistent for both male and female students. It is possible, based on previous research, females will report lower appearance and weight BE and higher SPA (Fitzsimmons-Craft, et.al., 2007; Kulavic, et.al., 2013), but research indicates these physical appearance variables are still a critical construct for college males (Martin, Kliber, Hodges Kulinna, \& Fahlman, 2006; Barlett, Harris, \& Bonds-Raacke, 2005). Because there are sometimes gender differences in these physical appearance variables, the results will be analyzed by gender.

\section{Method}

\section{Procedure and Participants}

Permission to collect data was granted by the University’s Internal Review Board. Students $\left(\mathrm{N}=555 ; 194\right.$ males and 359 females; $M_{a g e}=20.28, S D=2.34$; Male $M_{\text {age }}=20.61, S D=$ 2.97; Female $\left.M_{a g e}=20.01, S D=1.91\right)$ at a large Midwestern University enrolled in physical activity classes during the Spring 2015 were invited to complete a survey three weeks prior to the end of the semester. All participants completed informed consent forms. The survey assessed perceived climate, BE, SPA within the class, and demographic information. Instructors were not in the room while students were completing the surveys.

Of the participants, 79\% identified as Caucasian/White, with the remaining being African American/Black (6.3\%), Hispanic/Latino (4.7\%), Asian/Pacific Island (4.0\%), Native American $(0.9 \%)$, and as other $(5 \%)$. The majority of students were enrolled as freshmen $(30.3 \%)$, 
followed by seniors (28.3\%), sophomores (23.6\%), juniors (15.7\%), and graduate students (1.4\%). Physical activity classes included general exercise formats (e.g., boot camp, Zumba, yoga), sport-specific classes (e.g., racquetball, basketball, indoor soccer), and martial arts (e.g., Tae Kwon Do).

\section{Measures}

Motivational Climate. The abbreviated version of the Perceived Motivational Climate in Exercise Questionnaire (PMCEQ-A), developed by Moore, Brown, and Fry (manuscript under review), was used to measure the participants' perceptions of the motivational climate (task- or ego-involving) in their activity classes. The 12-item PMCEQ-A has two scales, a task- and egoinvolving scale, respectively. The stem, "In this class. .." was added before each item. Sample items included "In this class, students feel successful when they improve" (task-involving climate) and "In this class, the instructor praises students only when they do better than other students" (ego-involving climate). The PMCEQ-A employs a Likert response scale, with answers ranging from 1 (strongly agree) to 5 (strongly disagree). Moore, Brown, and Fry found support for the psychometric properties of the measure using confirmatory factor analysis with a college-aged population.

Caring Climate. The Caring Climate Scale (CCS), developed by Newton, et. al., (2007), was employed to measure the extent to which the participants' perceived the class environment to be caring. Like the PMCEQ, the scale is based on a 5-point scale ranging from 1 (strongly agree) to 5 (strongly disagree). The CCS was adapted to the activities class by adding the stem, "In this class. .. " to each of the 13-items. A sample item is, "In this class, students are treated with respect." Previous research has supported the psychometric properties of the CCS (Newton, et al., 2007; Iwasaki \& Fry, 2013). 
Body Esteem. Two of the three subscales of the Body-Esteem Scale for Adolescent and Adults (BESAA), developed by Mendelson, et. al. (2001), were used to assess a participant's overall body esteem (BE-Appearance and BE-Weight). The 18-items (10 appearance, 8 weight) asked participants to indicate how often they agreed with each item, ranging from $0=$ Never to 4 = Always (e.g., "I worry about the way I look" and "I am proud of my body"). Cronbach's Alphas were .92 and .94 for BE-Appearance and BE-Weight, respectively, as reported by Mendelson, et. al., in 2001.

Social Physique Anxiety. The 12-item version of the Social Physique Anxiety Scale (SPAS), developed by Hart, et. al. (1989), was used to assess a participant's anxiety related to the social evaluation of his/her body during the activities class. The SPAS uses a Likert response scale ranging from 1 (not at all) to 5 (extremely) and includes items as such, "In the presence of others, I feel apprehensive about my physique/figure." For this study, the stem, "In this class. .." was added to each item to assess individuals' anxiety specific to their exercise class environment. Item 12 , which addresses anxiety felt when in a bathing suit, was deleted since it is was only relevant to the students enrolled in swimming $(\mathrm{N}=16)$ and was not relevant for the majority of the participants in the study.

\section{Results}

Statistical analyses were conducted to determine descriptive statistics, Cronbach alpha reliability coefficients, and canonical correlation analyses using IBM SPSS version 22. Cronbach's reliability coefficients were all satisfactory and acceptable for each scale $(0.79-0.95)$ for the total sample, as well as for females and males. Mean scores indicated the total sample, as well as females and males considered separately, perceived a highly caring and task-involving and low ego-involving climate in classes. Descriptive analyses are presented in Table 1. 
ANOVAs were employed to examine potential gender differences on the six variables (climate, BE, SPA). Results revealed females perceived a modest but significantly lower ego-involving climate $[\mathrm{F}(2,550)=16.97, p<.001]$ and reported significantly lower BE-Appearance $[\mathrm{F}(2,543)$ $=20.23, p<.001]$ and BE-Weight $[\mathrm{F}(2,548)=20.57, p<.001]$ and higher SPA than males $[\mathrm{F}(2,545)=13.34, p<.001]$. Males and females perceived no difference in task-involving climate $[\mathrm{F}(2,550)=.60, p<.55]$, but perceptions of a caring climate approached significance $[\mathrm{F}(2,551)=2.33, p<.10]$

Pearson correlation analyses revealed a small, yet significant correlation between participants' perceptions of a highly caring and moderately task-involving climate with lowered SPA. There were also small, but significant positive correlations between caring and taskinvolving climates with $\mathrm{BE}$ appearance and $\mathrm{BE}$ weight. As expected, perceptions of a caring climate were positively correlated with a task-involving climate, while negatively correlated with an ego-involving climate. Likewise, BE-appearance was positively and significantly correlated with BE-weight, while negatively and significantly correlated with SPA. For all correlations, please refer to Table 1.

Canonical correlation analyses were conducted to examine the relationship between the climate variables (caring, task-, and ego-involving scales) to the BE variables (appearance and weight) and SPA for the total sample and for females and males separately. For the total sample, the canonical correlation analysis revealed one significant function $[\mathrm{L}=.94, F(9)=.06,(p<$ $.000)]$, and the canonical correlation was .24 with $5 \%$ overlapping variance. Loadings of .30 and above are considered in significant in canonical analyses (Tabachnick \& Fidell, 1996). The loadings revealed that perceptions of a highly caring and task-involving climate were associated 
with increased BE-Appearance and BE-Weight and decreased SPA. Please refer to Figure 1 for a visual representation.

The canonical correlation analysis for the females (see Figure 2) revealed one significant function $[\mathrm{L}=.94, F(9)=.06,(p<.01)]$. The canonical correlation was .24 with $6 \%$ overlapping variance. Similar to the total sample, females' perceptions of a highly caring and task-involving climate were associated with them reporting greater BE-Appearance and BE-Weight and lower SPA (see Figure 2).

For the males, the canonical correlation analysis revealed one significant function $[\mathrm{L}=.89$, $F(9)=.09,(p<.01)]$ (see Figure 3$)$. The canonical correlation was .29 with $8 \%$ overlapping variance. The loadings revealed that males' perceptions of a highly caring and task-involving climate, with a de-emphasis on an ego-involving climate were associated with them reporting greater BE-Appearance and BE-Weight and decreased SPA.

\section{Discussion}

The purpose of this study was to examine the relationship between students' perceptions of the motivational climate to their BE (i.e., appearance and weight) and SPA within physical activity classes. The hypothesis that students experiencing a caring and task-involving climate within their physical activity class would report greater BE and lower SPA was supported. One significant function emerged from the canonical correlation analysis. The loadings revealed that students' perceptions of a highly caring and task-involving climate were associated with their reporting higher body and appearance esteem and lower SPA. Though this single function was significant, the shared variance between the climate and physical appearance variables was small. 
Because gender difference in BE and SPA are sometimes noted in previous research (Paap \& Gardner, 2011), they were considered in this study. Males perceived a significantly higher ego-involving climate than females (i.e., approximately one-third point), while females reported significantly lower BE-Appearance and BE-Weight and higher SPA. Though these differences emerged, they did not impact the results examining the relationship between the students' perceptions of the climate to their physical well-being measures.

As hypothesized, the relationship between climate to BE and SPA was similar across gender. Results for female were nearly identical for the total sample. The results for males differed slightly from females and the total sample in that perceptions of an ego-involving climate contributed significantly to the canonical relationship. Specifically for the males, a strong de-emphasis on ego-involving climate features in combination with highly caring and taskinvolving aspects of the climate were associated with positive outcomes related to physical presence. This finding may have been due to the males reporting higher ego-involving climate scores, creating more variability within the scoring range. Canonical correlation results, overall, suggest that AGPT and a caring framework are relevant and offer information on how to enhance exercise settings for college students that are linked to positive outcomes related to them feeling better about themselves physically.

Research examining the link between participants' perceptions of the climate in physical activity settings to body appearance issues is limited, and there is much to consider in reviewing current research and planning future studies. Stark and Newton (2014) recently found with a sample of adolescent female dancers that their perceptions of a caring and task-involving climate were positively associated with their BE (using a composite score on the BESAA) and overall psychological well-being. These dancers were active in local studios and though it is difficult to 
judge their commitment to their sport, it is likely that they were more engaged than the college students in this study who were enrolled in general physical activity classes. The stronger relationship observed between climate and BE scores by these researchers in comparison to the present study could be related to these dancers' greater engagement and/or investment in the activity. For example, students in this sample participated in their activity for 50 minutes, two times per week, whereas those in Stark \& Newton's study averaged about eight hours per week. Further, body perceptions are known to be important for dancers and performers in activities where aesthetic features of the physical activity are critical (de Bruin, et.al., 2009). This may explain why relationships between the climate and $\mathrm{BE}$ variables were not as strong for this sample. It is also important to note that the BESAA has individuals think about their overall feelings about their weight and appearance, which are influenced by many factors in life outside of the students' involvement in the physical activity classes such as family dynamics, social interactions, and media representations (Tiggemann \& Williamson, 2000; Clark \& Tiggemann, 2007). It may be that the limited time individuals spend in the college physical activity classes was not enough to have a major impact on their perceptions of their weight and appearance.

In addition to $\mathrm{BE}$, researchers have also considered the association between climate to disordered eating. De Bruin, et. al. (2009), found gymnasts and dancers perceptions of a taskinvolving climate were negatively related to their disordered eating behaviors. Specifically, perceptions of a task-involving climate were associated with less dieting, feeling less weight pressure from coaches and peers, and greater self-esteem. Though not measured in this study, it would be interesting in future research to consider the association of a task-involving climate to healthy eating behaviors among exercisers. 
Where the measures of BE used in this study were more general, the SPA assessment had participants think about how anxious they were specific to being in the physical activity classes. This study was the first to examine the relationship between the climate to SPA, and results revealed a negative association between a caring and task-involving climate to SPA. The fact that the SPA measure was adapted to be specific to the class may explain why the relationships to the climate variables were stronger than with the general BE scales. Cox, Ullrich-French, Madonia, and Witty (2011) discovered in the high school physical education setting that individuals' feelings of peer-acceptance were negatively associated with SPA, with or without a friend present. While they did not specifically measure the participants' perceptions of the climate in class, peer acceptance is a feature of a caring climate and so these results are in line with the current findings.

Likewise, Anshel and Seipel (2007) did not measure perceptions of the motivational climate specifically, but found that college students' "doubts about actions," which refer to their confidence to exercise successfully was significantly positively correlated to their SPA. In the current study, males' perceptions of an ego-involving climate were associated with higher SPA. Findings across these two studies suggests that when college students doubt their exercise ability, as is more likely to occur in an ego-involving climate, it puts them at risk of experiencing SPA. However, future research is needed to further explore these relationships.

Limited research has examined the relationship between exercise climates to SPA, although Brown and Fry (2013) did investigate the relationship of exercise climates to participants' levels of tension and pressure. They found that participants perceiving a high caring and task-involving and low ego-involving climate within classes were more likely to report lower tension and pressure related to their exercise classes. These results are consistent with the 
findings of the current study in that if participants are perceiving the caring and task-involving features of the climate without the normative aspects of an ego-involving climate, they are likely to feel less tension and pressure in general, as well as concern over their physical appearance. Removing the constraints related to having feelings of stress, pressure, tension, and anxiety should help participants focus on more important aspects of the class like genuinely listening to the instructor's technical feedback instead of worrying about how they look performing exercises in comparison to others.

Perceptions of an ego-involving climate were not significantly related to the BE variables in this study, although an ego-involving climate has been linked to negative outcomes. For example, de Bruin, et. al. (2009), found that in a sport setting, gymnasts and dancers' perceptions of an ego-involving climate were related to engaging in more dieting and weight control behaviors, weight pressuring from peers and coaches, and perfectionism. These disordered eating behaviors are correlated with BE dissatisfaction (Henriques \& Calhoun, 1999), and can be detrimental for athletes to experience. Similarly, González-Cutre and Sicilia (2012) found exercise dependence is more likely to develop in an ego-involving exercise climate found in a gym. This is of concern because exercise dependence can also be an indicator of BE dissatisfaction (Garner, 2002). In the present study, the lack of significant correlations between perceptions of an ego-involving climate and physical appearance variables may be due to students perceiving a predominantly highly caring and task-involving climate. Though the evidence at this point is not strong linking an ego-involving climate to negative $\mathrm{BE}$ and exercise issues, it should be noted that an ego-involving climate is not being associated with positive health and exercise outcomes (e.g., BE) as is the case with a caring and task-involving climate. 
While this study has strengths in that it is one of the first to examine associations between exercise climates to BE and SPA, there are several limitations that should be noted. The sample include a unique group of exercisers, college students enrolled in semester-long physical activities classes for which college credit was granted. Generalizations to other exercise groups cannot be made based on these findings (e.g., corporate fitness, community fitness centers). Likewise, these classes included traditional exercise formats (e.g., boot camp, aerobic kickboxing, strength training) as well as sport-specific physical activities (e.g., swimming, racquetball) and martial arts (i.e., Tae Kwon Do and Self-Defense for Women). The effects of the climate on BE and SPA could vary across these different groups of activities and should be considered in future research. In addition, the instructors across these courses had diverse backgrounds, training and experience, and future research may examine how the instructors' training and teaching behaviors impact participants' perceptions of the climate, BE, and SPA. Climate, BE, and SPA could have interesting dynamics across a semester, which were not captured in this study, but future research should include multiple data points.

There are additional important avenues for future research along these lines. Body esteem is a complex variable that has many outside influences. The significant relationship of BE and SPA to a caring and task-involving climate is important, and suggests that a more positive and supportive climate results in heightened BE (appearance and weight) and lowered SPA within the class. It would be interesting to see how the compounding effects of perceptions of a caring and task-involving climate would affect physical appearance variables over a longer period of time, such as if students were enrolled in highly supportive environments multiple semesters during their college years. Along these lines, it could be valuable to include a mixed methods 
design to obtain qualitative data from participants to capture a richer and deeper picture of college students' exercise experiences and the impact on their BE.

Finally, a beneficial future direction would be to conduct interventions that create both caring and task-involving in contrast to ego-involving climates to examine how more extreme environments would lead to different outcomes specific to BE and SPA. Recently, Hogue, et. al., (2013) created these distinct physical activity climates and found that students assigned to the caring and task-involving climate reported greater pride, enjoyment, intention to continue to participate, and a lower cortisol response (i.e., lower stress). In contrast, college students in the ego-involving climate experienced greater shame, anxiety, less enjoyment, and greater cortisol production (i.e., stress response). These were climates that were extremely caring and taskinvolving versus extremely ego-involving, which sets the stage to examine variables of interest more closely than with general populations where the means can be more neutral.

This study contributes evidence to the positive impact creating a highly caring climate in the physical activity setting can elicit. It expanded current motivational climate and BE research in a mixed-gender exercise-specific setting and was one of the first to link climate and SPA, but considering that only one-third of college students engage in adequate physical activity and that BE issues are prevalent on college campuses (Keating, et.al., 2005), future research will be important in highlighting the relationship between motivational climate and BE. Evidence is mounting that exercise can play a key role in college students' healthy development so fitness professionals should strive to create a motivational climate that emphasizes caring and taskinvolving features and de-emphasizes ego-involving in order to optimize all participants' experiences within the exercise setting, including that of BE and SPA. 


\section{References}

Anshel, M.H., \& Seipel, S.J. (2007). Relationship between perfectionism and social physique anxiety among male and female college student exercisers. Perceptual and Motor Skills, 104, 913-922.

Barlett, C., Harris, R., Smith, S., \& Bonds-Raacke, J. (2005). Action figures and men. Sex Roles, $53(11 / 12), 877-885$.

Brown, T.C., \& Fry, M.D. (2013). Associations between females' perceptions of college aerobic motivational climates and their responses. Women \& Health, 53 (8), 843-857.

Brown, T.C., and Fry, M.D. (2014). Motivational climate, staff and members' behaviors, and members' psychological well-being at a national fitness chain. Research Quarterly for Exercise and Sport, 85(2), 208-217.

Brudzynski, L., \& Ebben, W.P. (2010). Body image as a motivator and barrier to exercise participation. International Journal of Exercise Science, 3(1), 14-24.

Cash, T.F., Melnyk, S.E., \& Hrabosky, J.I. (2004). The assessment of body image investment: An extensive revision of the appearance schemas inventory. The International Journal of Eating Disorders, 35(3), 305-316.

Cox, A.E., Ullrich-French, S., Madonia, J., \&Witty, K. (2011). Social physique anxiety in physical education: Social contextual factors and links to motivation and behavior. Psychology of Sport and Exercise, 12, 555-562.

Clark, L., \& Tiggemann, M. (2007). Sociocultural influences and body image in 9 to 12 -year-old girls: The role of appearance schemas. Journal of Clinical \& Adolescent Psychology,36(1), $76-86$.

Coppola, A.M., Ward, R.M., \& Freysinger, V.J. (2014) Coaches' Communication of Sport Body 
Image: Experiences of Female Athletes, Journal of Applied Sport Psychology, 26(1), 1-16.

Davis, C. (2002). Body image and athleticism. In T.F. Cash \& T. Pruzinsky (Eds.) Body Image: A Handbook of Theory, Research, and Clinical Practice (219-225). New York: The Guilford Press.

De Bruin, A.P., Bakker, F.C., \& Oudejans, R.R.D. (2009). Achievement goal theory and disorder eating: Relationships of disordered eating with goal orientations and motivational climate in female gymnasts and dancers. Psychology of Sport and Exercise, 10, $72-79$.

Fitzsimmons-Craft, E.E., Harney, M.B., Brownstone, L.M., Higgins, M.K., \& Bardone-Cone, A.M. (2012). Examining social physique anxiety and disordered eating in college women. The roles of social comparison and body surveillance. Appetite, 59, 796-805.

Fraser, S.N., \& Spink, K.S. (2002). Examining the role of social support and group cohesion in exercise compliance. Journal of Behavioral Medicine, 25 (3), 233-249.

Fry, M.D., \& Gano-Overway, L.A. (2010). Exploring contributions of the caring climate to the youth sport setting. Journal of Applied Sport Psychology, 22, 294-304.

Fry, M.D., Guivernau, M., Kim, M., Newton, M., Gano-Overway, L.A., \& Magyar, T.M. (2012). Youth perceptions of a caring climate, emotional regulation, and psychological wellbeing. Sport, Exercise, and Performance Psychology, 1, 44-57.

Garner, D.M., (2002). Body image and anorexia nervosa. . In T.F. Cash \& T. Pruzinsky (Eds.) Body Image: A Handbook of Theory, Research, and Clinical Practice (295-303). New York: The Guilford Press.

González-Cutre, D., \& Sicilia, Á. (2012). Motivation and exercise dependence: A study based on self-determination theory. Research Quarterly for Exercise and Sport, 83(2), 318-329.

Hagger, M.S., Hein, V., \& Chatzisarantis, N.L.D. (2011). Achievement goals, physical self- 
concept, and social physique anxiety in a physical activity context. Journal of Applied Social Psychology, 41(6), 1299-1339.

Harwood, C.G., Keegan, R.J, Smith, J.M.J., Raine, A.S.. (in press). A Systematic Review of the Intrapersonal Correlates of Motivational Climate Perceptions in Sport and Physical Activity, Psychology of Sport \& Exercise.

Hart, E. H., Leary, M. R., \& Rejeski, W. J. (1989). The measurement of social physique anxiety. Journal of Sport \& Exercise Psychology, 11, 94-104.

Hausenblas, H.A., \& Fallon, E.A. (2006). Exercise and body image: A meta-analysis. Psychology and Health, 21 (1), 33-47.

Henriques, G.R., \& Calhoun, L.G. (1999). Gender and ethnic differences in the relationship between body esteem and self-esteem. The Journal of Psychology, 133 (4), 357-368.

Hogue, C.M., Fry, M.D., Fry, A.C., \& Pressman, S.D. (2013). The influence of a motivational climate intervention on participants' salivary cortisol and psychological responses. Journal of Sport \& Exercise Psychology, 35, 85-97.

Hubbard, S.T., Gray, J.J., \& Parker, S. (1998). Differences among women who exercise for "food related" and "non-food related" reasons. European Eating Disorders Review, 6, 255265.

Huddleston, H., Fry, M.D., \& Brown, T.C. (2012). Corporate fitness members' perceptions of the environment and their intrinsic motivation. Revista de Psicolgogia del Deporte, 21 (1), $15-23$.

Iwasaki, S., \& Fry, M.D. (2013). The efforts of sport psychology professionals to assist sport administrators in evaluating youth sport programs. The Sport Psychologist, 27, 360-371.

Keating, X.D., Guan, J., Piñero, J.C., \& Bridges, D.M. (2005). A meta-analysis of college 
students' physical activity behaviors. Journal of American College Health, 54 (2), 116-125.

Koff, E., Benavage, A., \& Wong, B. (2001). Body-image attitudes and psychosocial functioning in Euro-American and Asian-American college women. Psychological Reports, 88, 917-928.

Krane, V., Greenleaf, C.A., \& Snow, J. (1997). Reaching for gold and the price of glory: A motivational case study of an elite gymnast. The Sport Psychologist, 11, 53-71.

Krane, V., Stiles-Shipley, J.A., Waldron, J., \& Michalenok, J. (2001). Relationship among body satisfaction, social physique anxiety, and eating behaviors in female athletes and exercisers. Journal of Sport Behavior, 24(3), 247-264.

Kulavic, K., Hultquist, C.N., \& McLester, J.R. (2013). A comparison of motivational factors and barriers among traditional versus nontraditional college students. Journal of American College Health, 61 (2), 60-66.

Martin, J.J., Kliber, A., Hodges Kulinna, P., \& Fahlman, M. (2006). Social physique anxiety and muscularity and appearance cognitions in college men. Sex Roles, 55, 151-158.

Martin Ginis, K.A. \& Leary, M.R. (2004). Self-presentational processes in health-damaging behavior. Journal of Applied Sport Psychology, 16, 59-74.

Mendelson, B.K., Mendelson, M.J., \& White, D. R. (2001). Body-esteem scale for adolescents and adults. Journal of Personality Assessment, 76(1), 90-106.

Moore, E.W.G, Brown, T.C., \& Fry, M.D. (under review). Psychometric properties of the abbreviated perceived motivational climate in exercise questionnaire.

Moore, E.W.G., \& Fry, M.D. (2014). Psychometric support for the ownership in exercise and empowerment in exercise scales. Measurement in Physical Education and Exercise Science, 18(2), 135-151.

Nelson, M.C., Kocos, R., Lytle, L.A., \& Perry, C.L. (2009). Understanding perceived 
determinants of weight-related behaviors in late adolescence: A qualitative analysis among college youth. Journal of Nutrition Education and Behavior, 41 (4), 287-292.

Newton, M., Watson, D. L., Gano-Overway, L., Fry, M., Kim, M., \& Magyar, M. (2007). The role of a caring-based intervention in a physical activity setting. The Urban Review, 39(3), 281-299.

Nicholls, J.G. (1984) Achievement motivation: Concepts of ability, subjective experience, task choice and performance. Psychological Review, 91, 328-348.

Nicholls, J.G. (1989). The competitive ethos and democratic education. Cambridge, MA: Harvard University Press.

Paap, C.E., \& Gardner, R.M. (2011). Body image disturbance and relationship satisfaction among college students. Personality and Individual Differences, 51, 715-719.

Pila, E., Stamiris, A., Castonguay, A., \& Sabiston, C.M. (2014). Body-related envy: A social comparison perspective in sport and exercise. Journal of Sport \& Exercise Psychology, 36, 93-106.

Roberts, G.C. (2012). Motivation in sport and exercise from an achievement goal theory perspective: After 30 years, where are we?. In G.C. Roberts \& D.C. Treasure (Eds.), Advances in Motivation in Sport and Exercise (5-58). Champaign, IL: Human Kinectics.

Stark, A., \& Newton, M. (2014). A dancer's well-being: The influence of the social psychological climate during adolescence. Psychology of Sport and Exercise, 15, 356-363.

Tabachnick, B. G., \& L. S. Fidell. (1996). Using multivariate statistics. New York: Allyn \& Bacon.

Tiggemann, M., \& Williamson, S. (2000). The effect of exercise on body satisfaction and selfesteem as a function of gender and age. Sex Roles, 43, 119-127 
Waldron, J.J., \& Krane, V. (2005). Whatever it takes: Health compromising behaviors in female athletes. Quest, 57, 315-329 


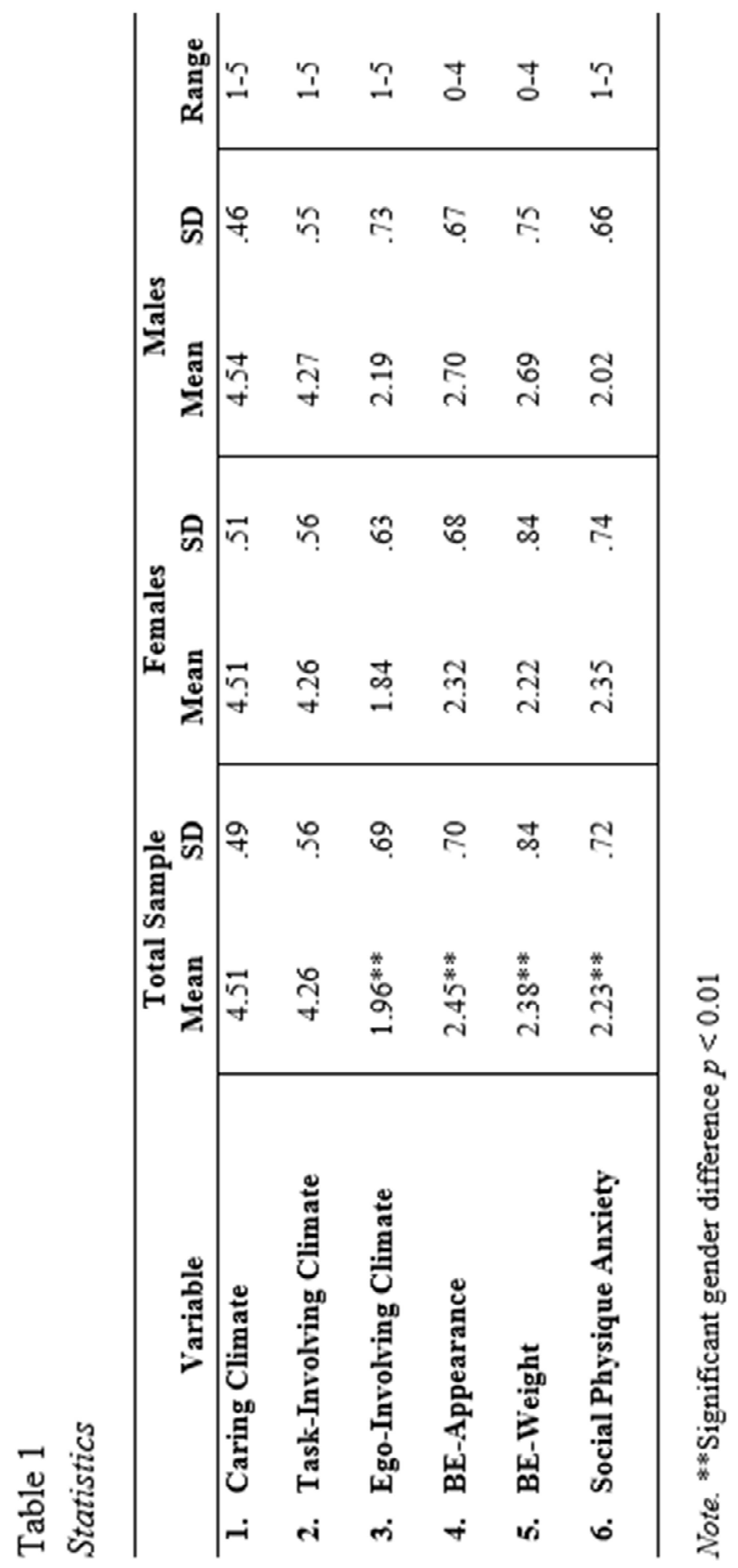




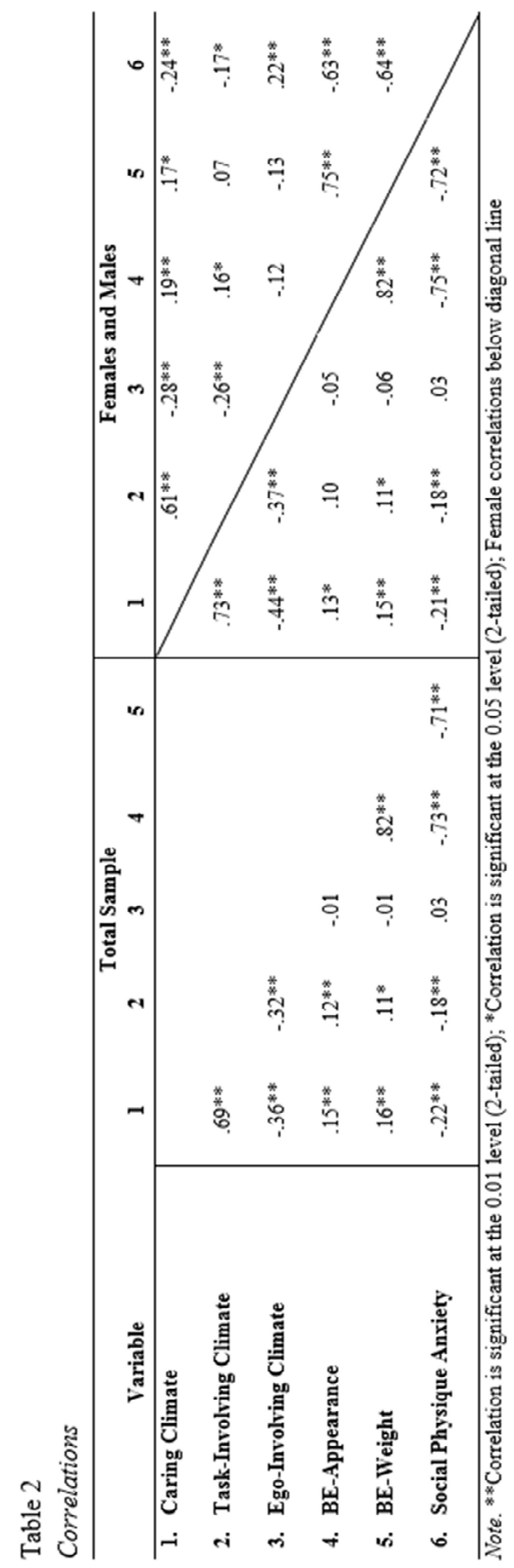


Figure 1

Canonical Correlation Analysis for Total Sample (both Males and Females)

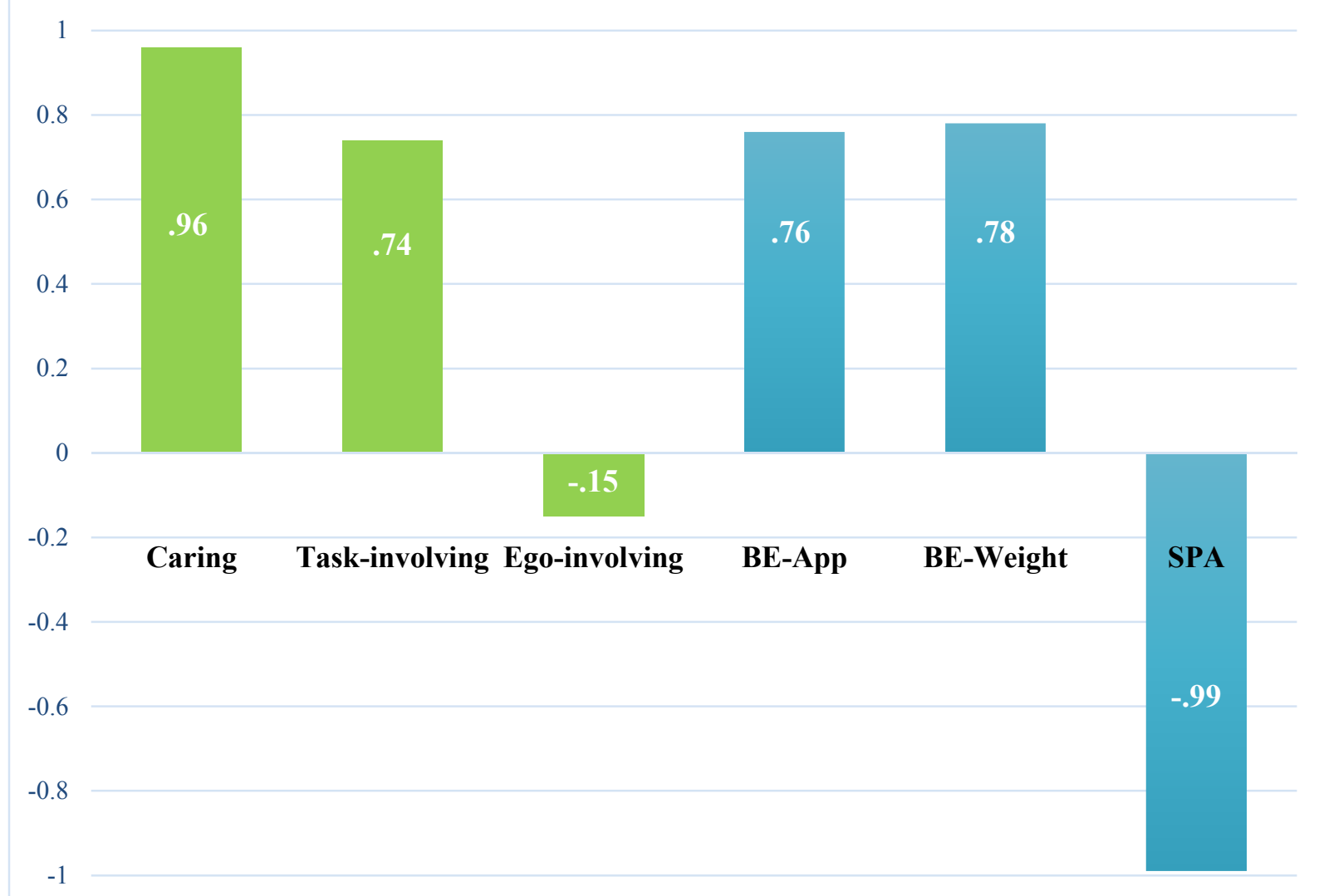

Note. BE-App refers to body esteem appearance. BE-Weight refers to body esteem weight. Loadings above +/-.30 considered meaningful 
Figure 2

Canonical Correlation Analysis for Females

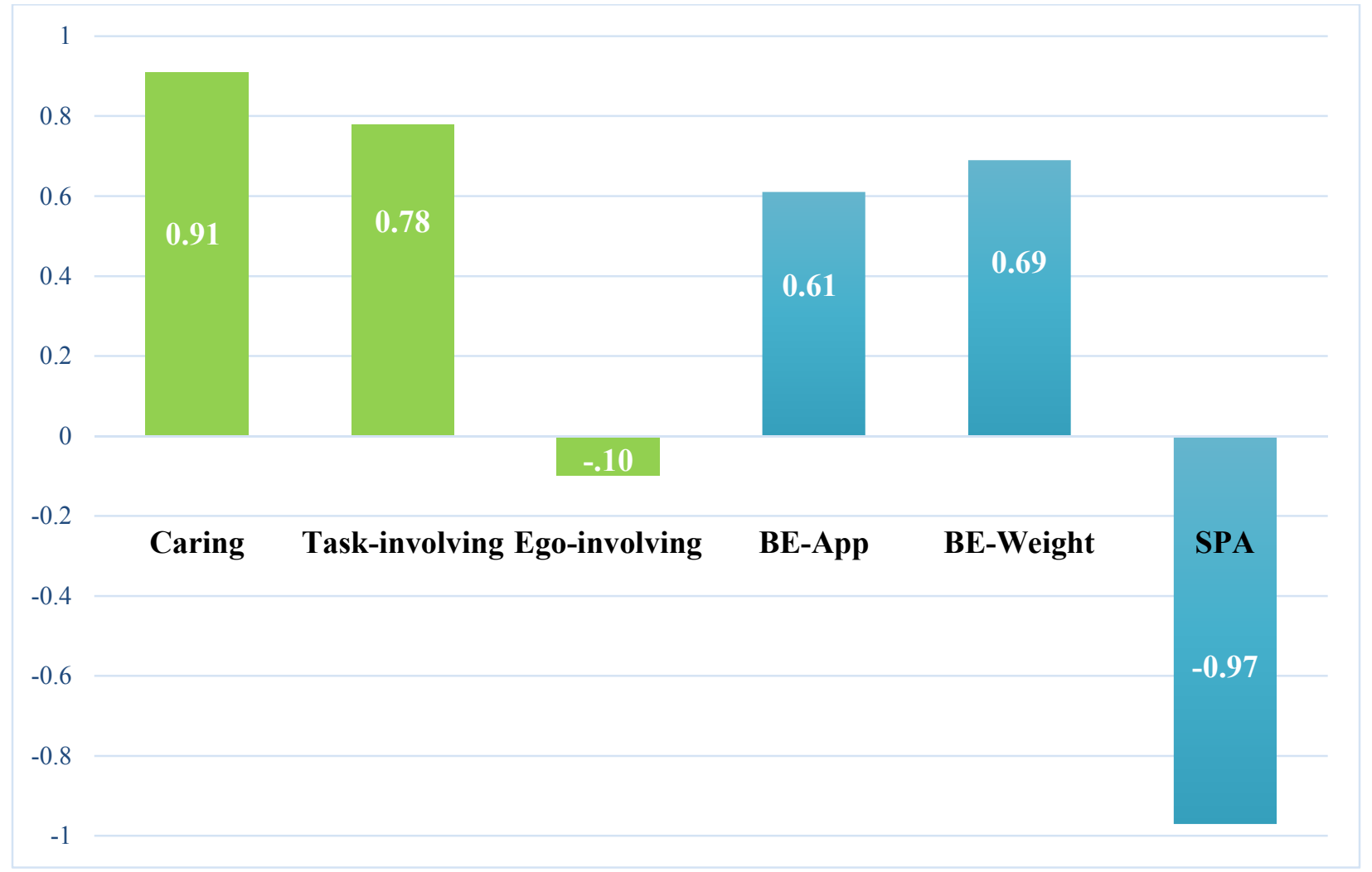

Note. BE-App refers to body esteem appearance. BE-Weight refers to body esteem weight. Loadings above $+/-.30$ considered meaningful 


\section{Figure 3}

Canonical Correlation Analysis for Males

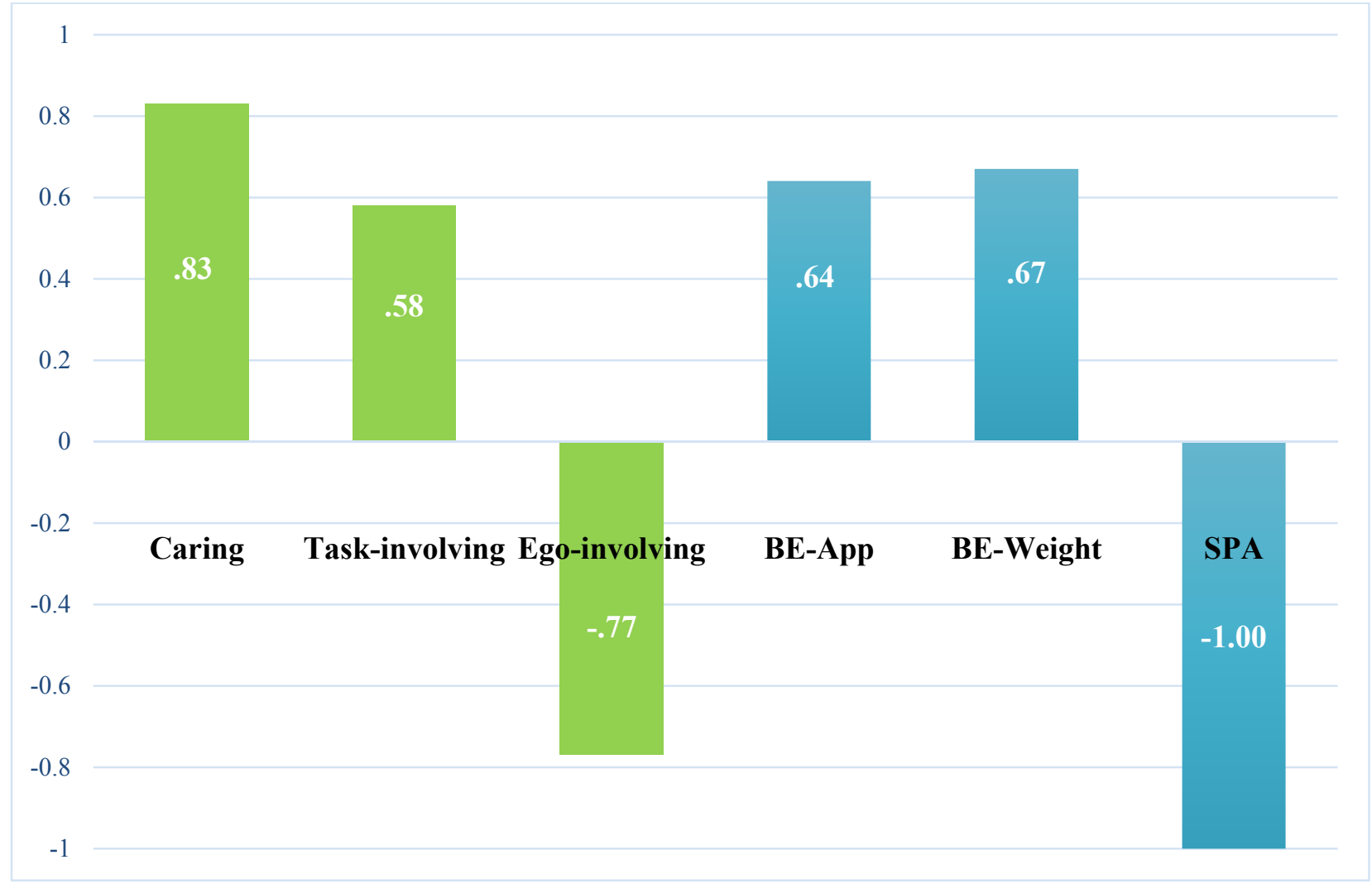

Note. BE-App refers to body esteem appearance. BE-Weight refers to body esteem weight. Loadings above +/-.30 considered meaningful 
Appendix A:

\section{IRB Approval}




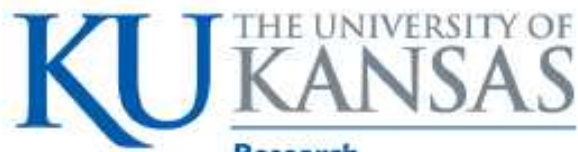

Research

January 7,2015

Sheryl Miller

kusheryl@ku.edu

Dear Sheryl Miller:

\section{APPROVAL OF PROTOCOL}

On $1 / 7 / 2015$, the IRB reviewed the following submission:

\begin{tabular}{|c|c|}
\hline Type of Review: & Initial Study \\
\hline Title of Study: & $\begin{array}{l}\text { Motivational climate is a predictor of body esteem in } \\
\text { college student fitness classes }\end{array}$ \\
\hline Investigator: & Sheryl Miller \\
\hline IRB ID: & STUDY00002030 \\
\hline Funding: & None \\
\hline Grant ID: & None \\
\hline Documents Reviewed: & $\begin{array}{l}\text { - S Miller Cover Letter.docx, • Final } \\
\text { HSCL_signed_consent_form_7_13 Miller.docx, • } \\
\text { Proposed Measures, • } \mathrm{HSCL}_{\text {Initial_Submission_Form.pdf, }}\end{array}$ \\
\hline
\end{tabular}

The IRB approved the submission from $1 / 7 / 2015$ to $1 / 6 / 2016$.

1. Before $1 / 6 / 2016$ submit a Continuing Review request and required attachments to request continuing approval or closure.

2. Any significant change to the protocol requires a modification approval prior to altering the project.

3. Notify HSCL about any new investigators not named in original application. Note that new investigators must take the online tutorial at https://rgs.drupal.ku.edu/human subjects compliance training.

4. Any injury to a subject because of the research procedure must be reported immediately.

5. When signed consent documents are required, the primary investigator must retain the signed consent documents for at least three years past completion of the research activity.

If continuing review approval is not granted before the expiration date of $1 / 6 / 2016$ approval of this protocol expires on that date.

Please note university data security and handling requirements for your project:

https://documents.ku.edu/policies/IT/DataClassificationandHandlingProceduresGuide.htm

You must use the final, watermarked version of the consent form, available under the "Documents" tab in eCompliance.

Sincerely,

Stephanie Dyson Elms, MPA

IRB Administrator, KU Lawrence Campus 
Appendix B:

\section{EXTENDED LITERATURE REVIEW}




\section{Introduction}

With almost half of Americans (aged 18-24) enrolled in post-secondary institutions, it is important to examine factors that enhance well-being during this time period (Nelson, Kocos, Lytle, \& Perry, 2009). Positive body image and regular physical activity are both factors that contribute to overall well-being (Cash \& Pruzinsky, 2002; Brown \& Fry, 2013). However, this transitioning period between adolescence and independent adulthood is often marked by adverse health behaviors (e.g., alcohol consumption, inappropriate nutrition, sleep deprivation; Nelson, et. al., 2009) that contribute to decreased body image satisfaction. As a global indicator of wellbeing, it seems imperative that body image be bolstered as best it can in the college years. Yet, this period in life is often marked as one of body image dissatisfaction (Paap \& Gardner, 2011).

Young adulthood is the time when lifestyle habits (such as physical activity) are established (Kulavic, Hutlquist, \& McLester, 2013), so it is important to not only understand how to optimize motivation to be physically active for a more functional adulthood, but also to increase body image satisfaction while doing so for increased well-being. This literature review aims to discover what research is available on how to best optimize motivation, body image development and influences, as well as the benefits of creating a positive and supportive exercise environment for college students.

\section{Achievement Goal Perspective Theory}

According to the President's Council on Fitness, Sports, and Nutrition (2014), only one in three adults participate in the recommended amount of physical activity per week, while the World Health Organization (WHO; 2014) notes that physical inactivity is the fourth leading risk factor for global mortality. These striking statistics necessitates the use of a theory that enhances individual's motivation to exercise. With more than 25 years of research supporting its tenets, 
Achievement Goal Perspective Theory (AGPT) provides a sound social cognitive framework for understanding how to optimize individuals' motivation. Developed by John Nicholls (1984; 1989), AGPT aims to explain how individuals define success and develop specific goals, while also exploring how the environment surrounding them affects their definitions of success. Already researched in the education (e.g., Ames, 1992) and sport setting (e.g., Reinboth \& Duda, 2005), the most recent realm to adopt its beliefs is the physical activity setting (Brown \& Fry, 2013).

Nicholls argued that individuals have a natural motivation to exhibit proficiency for any given task. With regard to their perceptions of competencies, individuals can be task-involved and/or ego-involved. Task-involved individuals are focused on their own effort and improvement. Contradictory to that, ego-involved individuals focus on normative standings, or how they are doing compared to others. Nicholls refers to these two states of involvement as goal perspectives. Whether an individual is task- or ego-involved for a particular setting is dependent on his/her cognitive development, goal orientation, and motivational climate (Nicholls, 1984; 1989).

\section{Cognitive Development}

Until approximately the age of 12 years, Nicholls proposed that children are naturally task-involved. This is because they are lack a mature understanding of ability (Fry \& Duda, 1997; Nicholls, 1984). For instance, a young child might believe that trying hard is exactly the same as having high ability, regardless of the outcome. Children might also believe luck is the same as ability. There are four levels that children progress through before they are able to clearly understand the difference between luck, effort, and ability to perform tasks (Fry \& Duda, 2007; Nicholls, 1989). 
At level one, children believe effort, ability, and outcomes are one and the same. They believe if a person tries hard, he/she will achieve the necessary outcome. They do not comprehend that a person can try hard but still fail to achieve the expected goal. At level two, children begin to recognize differences in ability among individuals. However, they still maintain the person putting forth the most effort will perform the best. Level three is a transitional period where children sometimes view effort and ability as differentiated, though responses are inconsistent (Fry \& Duda, 1997). It is not until level four that children can clearly distinguish between effort and ability. At this level, children finally understand that low effort with high performance indicates high ability.

Only when children recognize their effort can help with their performance, and that their performance is dependent on their current ability, can they learn to accurately compare themselves to those around them (Fry \& Duda, 1997; Nicholls, 1989). Thus, once children develop a mature understanding, they become capable of displaying an ego goal perspective

\section{Goal Orientations}

In AGPT, Nicholls argues that as children obtain a mature view of ability, they choose how they will define success. These definitions of success are referred to as goal orientations and can be task and/or ego. Individuals high in task orientation define success based on their personal effort and improvement. Their focus is on their own progress and greater gain in mastery of a skill (Duda \& Nicholls, 1992).

In contrast, individuals high in ego orientation feel successful when their ability compares favorably to others. Specifically, they feel successful when they outperform, or complete the same task with less effort than, others (Nicholls, 1989). Goal orientations are orthogonal, meaning an individual can have any combination of task and ego orientations (i.e., 
high in both; high in one and low in the other; low in both), and their goal orientations can change in different settings (Roberts, 2012).

Goal orientations predict how individuals will respond in an achievement setting. For example, if individuals high in ego orientation perceive they have high ability compared to those around them, they will be more likely to seek out challenges, give their full effort, and persist in the face of obstacles. Contrarily, if highly ego-involved individuals perceives low ability compared to those surrounding them, they are more likely to give-up, avoid challenges, and give lower efforts. The same is not true for individuals high in task orientation. Regardless of perceived ability, they are likely to give their best effort, strive to overcome obstacles, and welcome challenges (Nicholls, 1989).

Within the physical education setting, research suggests individuals high in task orientation (regardless of low or high ego orientation) have more adaptive behaviors. Standage and Treasure (2002) surveyed 318 middle-schoolers' goal orientation and situational motivation (e.g., "While you are engaged in Physical Education. ..") and found that task orientation was positively correlated with more intrinsic motivation and negatively associated with extrinsic motivation and amotivation. In a similar vein, Spray and Wang (2001) measured goal orientations, perceived competence, reasons for good behavior, and self-reported discipline in middle school PE, concluding that task-oriented students were more likely to concentrate on learning, desire an orderly working environment, and report lower ratings of discipline than the ego-involved group.

\section{Motivational Climates}

In addition to cognitive development and goal orientations, the third factor influencing whether individuals are task- or ego-involved is their perceptions of the environment in their 
group setting. Nicholls refers to these as motivational climates, and they can be either task- or ego-involving. Unlike goal orientations, these are not orthogonal (Roberts, 2012). Within an achievement setting, perceptions of the motivational climate are influenced by the instructor(s).

To create an ego-involving climate, instructors use competition and normative standards of performance to define individuals' ability (Nicholls, 1989). Thus, rivalries among participants are encouraged and only those with high ability are recognized and rewarded. Students' perceptions of an ego-involving climate are consistently related to maladaptive behaviors, such as increased rates of cheating, decreased effort, and increased anxiety (Harding, 2015).

In a task-involving climate instructors reward and emphasize personal effort and improvement (as opposed to normative comparison), foster cooperation among participants, and help everyone to feel valued and welcomed (Nicholls, 1989; Huddleston, et.al., 2012). Nicholls believed creating a task-involving climate was the key to maximizing motivation for all participants within the environment (Smith, Fry, Ethington, \& Li, 2005). Task-involving climates have been consistently linked to greater effort, morally-sound methods of reaching goals, and greater enjoyment of activity (Harding, 2015).

In order to fully help others feel valued and encourage cooperation, an instructor must also create a caring climate to complement the task-involving climate. The concept of caring was first advocated by Nel Noddings (1995) in the school setting. She noted that to create a caring relationship, there must be a carer and a cared-for (Noddings, 2012). Both parties must be involved in a non-biased and non-judgmental manner, both must be open, receiving, and empathetic to each other, and both must realize the cared-for is a top priority (Noddings, 2010, 2012). Teachers who create caring relations genuinely listen, model caring behaviors, and provide for open-ended dialogue with and between their students (Noddings, 1992). This 
“provides psychological safety, security, and connection needed to fully develop unique capabilities and strengths" (Newton, Watson, Gano-Overway, Fry, Kim, \& Magyar, 2007, p. 284).

Battistich, Solomon, Watson, and Schaps (1997) expanded upon Noddings’s caring concept to create a caring environment within the school setting and examined the benefits of such efforts. More recently, a group of sport and exercise psychology researchers have defined this environment as a caring climate, where the instructor consistently and intentionally attempts to generate an interpersonally safe, inviting, and supportive environment to all involved (Newton, et. al., 2007).

Despite its theoretical origins in the school setting, the creation of a caring climate has transitioned well into the physical activity domain. Those perceiving a caring climate report greater empathy toward others within the activity, greater commitment to as well as enjoyment of the activity, and a sense of belonging to the activity (Fry \& Gano-Overway, 2010; Newton, et. al., 2007; Brown \& Fry, 2013). For example, Newton, et. al., (2007) created a caring curriculum that was implemented during a summer physical activity camp for under-served youth. Using a “comparison group design" (2007, p. 284), this curriculum compared a caring-based climate to a traditional-based climate. They found that in a caring climate, not only were participants' perceptions negatively correlated with an ego-involving climate, but that participants had greater empathy for others in the program and expressed a greater desire for future participation. Larson (2006) also applied a caring climate curriculum to a physical education setting, finding that elementary and secondary students perceived that instructors paid attention to students, as well as treated them with respect, trusted them, and assisted in student learning. Instructors noted greater student engrossment as a result. 
Caring and task-involving climates are positively correlated, and when perceived simultaneously, have been linked to more adaptive behaviors such as greater effort, enjoyment, self-confidence, and exercise adherence (Brown and Fry, 2013; 2014; Hogue, et. al., 2012; Moore \& Fry, 2014). These outcomes are necessary to establish appropriate physical activity habits. On the other hand, ego-involving climates have been linked to more maladaptive behaviors such as greater self-consciousness, shame, somatic anxiety, and less enjoyment (Hogue, et. al., 2012).

Specifically within the exercise setting, perceptions of a caring, task-involving climate have been linked to many positive outcomes such as greater exercise adherence, increased effort, enjoyment, and self-confidence. Moore and Fry (2014) surveyed college group exercise participants and found that their perceptions of a caring and task-involving climate were positively correlated to their sense of empowerment and ownership in exercise, whereas perceptions of an ego-involving climate were negatively correlated. Similarly, when Brown and Fry (2013) surveyed college females in the group exercise setting, they found that participants who perceived a caring and task-involving climate were more likely to report that they exercise for enjoyment, health, and fitness reasons. Both studies indicate that instructors play "an important role in helping students have a positive experience" (Brown \& Fry, 2012, p. 853).

\section{Body Image}

Body image is defined as an individual's perceptions and attitudes surrounding his or her own physical characteristics (Cash \& Pruzinsky, 2002). Instead of being a stable construct, body image is a dynamic and constantly developing mental representation of the body's self and the basis for self-representation (Krueger, 2002). Cash and Pruzinsky (2002) note that body image includes the importance people attribute to their looks, as well as how satisfied they are with 
their looks (Jonsdottir, et.al., 2009). Across cultures, body image is associated with self-esteem and global self-worth. In addition, body image attitudes have been linked to interpersonal confidence, eating and exercise behaviors, and emotional stability (Cash \& Fleming, 2002b; Thompson, et al, 1999). Having a negative body image can have adverse psychosocial consequences (Cash, et al, 2004), including disordered eating, depression, and social anxiety. Likewise, poor body image is associated with low self-esteem and other psychological impairments (Koff, Benevage, \& Wong, 2001).

Body image is multidimensional, so there are various ways to quantify it. Body esteem is often measured as an indicator of individuals' overall body image. Defined by Mendelson, Mendelson, and White (2001), body esteem is the self-evaluation of one's body or appearance that is also a global construct that positively correlates with self-esteem. Like body image, low body esteem has also been associated with increased risk of depression, anxiety, and low selfesteem (Henriques \& Calhoun, 1999).

\section{Body Image Across the Lifespan}

Body image develops and changes as individuals mature. Though little is known about the development of body image in young children (Smolak, 2004), there is empirical evidence to suggest that girls as young as six are aware of the concept of dieting and being dissatisfied with their bodies (Lowes \& Tiggemann, 2003). How children focus on their body weight or shape is the result of individual (e.g., gender or BMI) and sociocultural (e.g., comments from parents or media regarding shape expectations) variables (Clark \& Tiggemann, 2007; Smolak, 2002).

A study conducted by Mccabe, Ricciardelli, and Salmon (2006) found that third through sixth grade boys focused on muscle growth, while the same grades of girls focused on their weight. The same boys expressed a greater dissatisfaction with their muscle size, whereas the 
girls were more dissatisfied with their current weight (p. 595). This is important to understand, because body dissatisfaction early in life is often a precursor to body image disorders (Clark \& Tiggemann, 2007).

As young children transition into adolescence, body image becomes a more dominant subject. Puberty onset means changing bodies that are not always welcomed. Girls may not understand why their bodies are gaining weight and boys hitting puberty later than others are atrisk of being teased for their smaller and less developed bodies. In general, however, girls tend to have a more negative body image than boys in adolescence (Levine \& Smolak, 2002;

Tiggemann, 2001). This is due mostly to puberty-induced weight gain at a time of emerging sexuality, differentiated identity from childhood, and increased consumption of pop-culture media encouraging a thinner ideal body frame (Levine \& Smolak, 2002; Tiggemann, 2001; Clark \& Tiggemann, 2007).

Moving from adolescence to young adulthood is another time of crucial body image development and perhaps explains why the topic of body image in the college population has a wealth of research. Many college students experience countless stressors that can result in body image distress. Transitioning from high school to college often includes increased autonomy with food and physical activity choices. Dorm food choices, lack of structured physical activity once found in sports or gym class, and increased alcohol intake can result in unexpected weight gain (Nelson, Kocos, Lytle, \& Perry, 2009; Vella-Zarb \& Elgar, 2010; LaCaille, Dauner, Krambeer, \& Pedersen, 2011). Adjusting to a new environment that includes balancing a social life with school work often means healthy behaviors, such as physical activity, become a low priority (Nelson, et. al., 2009; LaCaille, et. al., 2011). 
The college years are also a time when many young people are expanding their social group. Gillen and Lefkowitz (2006) noted that with new friends can potentially come new social comparisons. Increased peer-dominated environments (e.g., sororities or potential dating partners) often emphasize appearance that promote changes in individuals' body image. SmithJackson and Reel (2012) conducted a qualitative study that explored college women's freshmen experiences, including body image. A theme that emerged was increased social comparison with both friends and strangers. This resulted from university students' competition to attract the opposite sex, as well as to maintain a pre-college appearance as many participants cited familial concerns over gaining weight. These comparisons lead many college students to feel inadequate.

Furthermore, social comparisons can result in obsessive calorie monitoring and maladaptive exercise habits (2012). Additionally, most of the empirical research on "fat talk" is with undergraduate females, implying college women engage in conversations regarding their bodies frequently (Salk \& Engeln-Maddox, 2011; Nichter, 2000). Coined by anthropologist Mimi Nichter, "Fat Talk" is the tendency to make negative comments about one's body and often implies one feels fat, even if the person is not overweight. Nichter also states this is a metaphor for feeling down (Goodman, 2011).

Research suggests older adults may have body dissatisfaction, but the psychological impacts (increased body monitoring, anxiety) decrease (Striegel-More \& Franko, 2002). Middleage and older adults tend to mark body image satisfaction not only by the media and interpersonal influences, but also on their physical health and competence (Whitbourne \& Skultety, 2002). Physical functioning compromised due to age is often when adults express a more negative body image (Krauss Whitbourne \& Skultety, 2002). 


\section{Gender and Body Image}

Today it is recognized that both men and women encounter body image issues (Smolak, 2004; Cash \& Pruzinski, 2002). In addition, research suggests that body dissatisfaction in men and women is increasing at a faster rate than ever before (Sheldon, 2010) and starts at a young age. Prepubescent boys are more likely to report a desire for bigger muscles, whereas girls across age spans express a wish for thinner bodies. Also, women report greater body dissatisfaction earlier in life than compared to men (Smolak, 2002).

Where women report wanting to lose body fat in order to appear thinner, men report doing so to better define their muscular stature (Olivardia, 2002; Kulavi, K., Hultquist, C.N., \& McLester, J.R., 2013). Many men cite a body image ideal of having bigger muscles. This becomes problematic when anabolic steroid and food supplements are misused and/or abused (Barlett, et.al., 2005). Despite its advances in research in recent years, men and body image remains an area where research is sorely needed (Olivardia, 2002; Smolak, 2004).

The drive to be thinner or to increase muscle mass has been linked to disordered eating and substance abuse (e.g., steroids or laxative use). This behavior, when left untreated, is likely to result in eating disorders or other body image disturbances, such as body dysmorphic disorder (Garner, 2002).

\section{Other Influences on Body Image Development}

The sociocultural factors of the media and interpersonal relationships with peers, parents, and strangers are the most commonly cited contributors to the development of body imagenegative or positive (Smolack, 2004; Clark \& Tiggeman, 2007; Vander Wal \& Thelen, 2000; Lowes \& Tiggemann, 2003; Cox, Ullrich-French, Madonia, \& Witty, 2011; Cash \& Pruzinsky, 2002). 
In children, parents and peers are the greatest influence. Studies show parents' comments — on their own or their child's appearance—whether intentionally or otherwise, can have detrimental effects on the child's body image development (Clark \& Tiggemann, 2007). For example, Lowes and Tiggemann (2003) show that children are aware of their parents' body dissatisfaction, and those whose parents express greater body dissatisfaction also express a greater dissatisfaction with their own bodies.

As noted, peers also influence individuals' body image satisfaction. Appearance-related teasing is the most common form of teasing among children (Smolak, 2004), with boys reporting more negative comments than girls (2004). On the other hand, girls are more likely to engage in conversations of their bodies compared to others (Nichter, 2000).

Peers and parents continue to influence body image development throughout adolescence and well into adulthood. Female college students often engage peers in fat talk, and SmithJackson and Reel (2012) noted many college students hear verbal family concern over their student gaining weight. These can contribute to poor body image. Furthermore, the media becomes a bigger influencer as females and males age.

In her chapter of Body Image: A Handbook of Theory, Research, and Clinical Practice, Tiggemann (2002) reported that, as a whole, research supports a link between media exposure and body image. The Western world inundates media sources (e.g., magazines, television, social media) with sources of tall, thin female figures and lean, muscled male bodies. Since most body image research has focused on females, recent advertising campaigns in the media have aimed at including more diverse body female types. Still, these tend to emphasize thinness and are not representative of the general population (Beauty Redefined, 2014). 
Likewise, a study conducted by Barlett, Harris, Smith, and Bonds-Raacke (2005) discovered that males' handling highly muscular action figures reported significantly lower mean scores on the body esteem scale compared to those that did not (p. 884). Sylvia, King, and Morse (2014) also found that males in an experimental group playing a highly realistic video game with a character of exaggerated muscularity reported significantly lower body satisfaction than men in the control group playing with a character of average build. It is clear there is still a long way to go in creating a world where the media accurately represents the people to which it advertises.

Although it is true not every person exposed to inaccurate, idealized body types in the media develop adverse reactions to it, these portrayals have been empirically linked to disordered eating and body image disorders, such as Social Physique Anxiety (SPA; Tiggemann, 2001; Clark \& Tiggemann 2007; Smolak, 2004; Garner 2002; Fitzsimmons-Craft, Harney, Brownstone, Higgins, \& Bardone-Cone, 2012; Foreyt, 2010; Krane, Stiles-Shipley, Waldron, \& Michalenok, 2001; Cox, Ullrich-French, Madonia, \& Witty, 2011).

\section{Physical Activity, Social Physique Anxiety, and Body Image}

Research has shown body image can be both a motivator and barrier to exercise (Brudzynski \& Ebben, 2010; Davis, 2002). The association between body satisfaction and physical activity is complex with several factors mitigating whether physical activity enhances or hinders body image (Davis, 2002). Motivation for exercise is often connected to an individual's attitudes about weight, which is, consequently, related to body image. For example, men and older adults most commonly experience a positive association between physical activity and body image, whereas exercise in younger women (ages 16-21 years) is negatively associated with body satisfaction - especially if they engage in exercise to change the shape of their bodies (Davis, 2002; Tiggemann \& Williamson, 2000; Hubbard, 1998). 
Social Physique Anxiety (SPA), a subtype of social anxiety, occurs when an individual believes his/her body is being negatively evaluated by others around him/her, resulting in feelings of anxiety or apprehension (Hart, Leary, \& Rejeski, 1989; Krane, et.al., 2001). In the sport and physical activity domains, there is sometimes an erroneous assumption that a thinner body results in better performance (Waldron \& Krane, 2005; Krane, et.al., 1997; Coppola, Ward, \& Freysinger, 2014). This belief, coupled with SPA, can lead to either exercise avoidance or addiction, and other negative health behaviors (Krane, et.al., 2001; Martin, Ginis, \& Leary, 2004).

On the other hand, if an exerciser does not experience social physique anxiety, regular physical activity can result in a more positive body image (Hagger, Hein, \& Chatzisarantis, 2011). For example, Tiggemann (2001) found that girls in sports reported lower body dissatisfaction. She surmised this was probably due to the fact the body was given a function other than being a decoration, where one must be "thin and attractive" (p. 139).

\section{Body Image and Motivational Climate}

Social comparison has been shown countless times to result in decreased body image satisfaction (Fitzsimmons-Craft, et.al., 2012; Smith-Jackson \& Reel, 2012; Sides-Moore \& Tochkov, 2011; Cash \& Fleming, 2002a). For example, Sides-Moore \& Tochkov (2011) presented college participants with an image of an attractive model. After comparing their own bodies to the picture, participants expressed significantly higher negative feelings about their body image. In the same study, the authors noted that competitiveness (e.g., to be thinner or better than others in your social group) was found to contribute positively to body image dissatisfaction. Competition and rivalries are encouraged in the ego-involving climate, so it seems likely this could result in increased competitiveness and thus, body image dissatisfaction. 
Cox, Ullrich-French, Madonia, and Witty (2011) discovered in the physical education setting that individuals with feelings of peer-acceptance led to decreased SPA. A caring/taskinvolving climate aims at fostering cooperation among participants, which suggests peeracceptance would be greater, and thus, decreasing SPA. In the physical activity setting, individuals may perceive that others are evaluating their physique and skill level, which can lead to anxiety (Krane, et. al., 2001). This seems likely to be exacerbated in an ego-involving climate, where an individual is constantly evaluating one's skill compared to others in the setting. Likewise, Fitzsimmons-Craft, et.al. (2012), discovered that individuals high in SPA who reported high levels of social comparison reported higher levels of disordered eating than those high in SPA but with low levels of social comparison. This seems to indicate that a caring/taskinvolving climate might mediate the effects of SPA.

Given that body image development is a lifelong process that can be influenced by interpersonal interactions (like those created in a fitness setting), and given how it is linked with a person's global self-esteem, it is important to recognize how climates created in the physical activity setting can affect it. It is important for instructors to create an environment that motivates all individuals and to understand which perceived motivational climate is most appropriate for enhancing positive body image.

In summary, body image dissatisfaction is often a result of perceived evaluation of one's body often aggravated by social comparison and competitiveness. An ego-involving climate promotes comparisons which can include the physical shapes of individuals and a caring and task-involving climate focuses on accepting all individuals as well as focusing on personal efforts. Therefore, an area of interest is studying the link, if any, between body image satisfaction and motivational climate. 


\section{Current Research}

It is vital for fitness professionals to understand how motivational climates affect body image. Yet, current research relating body image and AGPT is sparse. Bruin, et. al., (2009) found that, in a sport setting, both ego orientation and perceptions of an ego-involving climate were related to lower self-esteem and more dieting and weight-related peer pressure in gymnasts and dancers. Conversely, a task-involving climate was negatively related to disordered eating. Because disordered eating, and eating disorders in general, are correlated with body image dissatisfaction (Garner, 2002), this might indicate that AGPT can play a role in helping or hindering body image satisfaction.

In "Reaching for Gold and the Price of Glory: A Motivational Case Study of an Elite Gymnast" (1997), Krane, Greenleaf, and Snow examined the motivational climate of a former elite female gymnast and how it affected her self-perception and health behaviors. The qualitative data suggested the gymnast was surrounded by an ego-involving climate. In this climate, winning, social comparison, and perfectionism were emphasized. From this, the young gymnast exhibited low self-esteem and, only after being in this particular climate, developed an eating disorder. The symptoms manifested themselves in disordered eating, overtraining, and competing even when injured. It is interesting to note that after leaving the competitive environment, she was able to recover from her disordered eating.

In a recently published study measuring caring climate in addition to the ego- and taskinvolving climate, Stark and Newton (2014) surveyed non-elite dancers' perception of the climate in their programs and their well-being, which included body esteem. They found that a caring, task-involving climate or one that de-emphasized an ego-involving climate was related to greater body esteem as well as positive overall well-being. This makes sense in light of 
characteristics of the climates. The cooperative nature and nurturing environment of the taskinvolving climate would result in greater acceptance and support, which leads to feeling less selfconscious about self and appearance. Conversely, perceptions of an ego-involving climate would result in greater comparisons among participants, resulting in greater self-consciousness about one's self and appearance. It may well be that these findings might be replicated in an exercise setting.

Specific to the physical activity domain, in a mixed-gender study examining motivational climate and self-determination theory, González-Cutre and Sicilia (2012) found that exercise dependence (i.e., exercise addiction) is more likely to develop in an ego-involving climate. Comparisons between exercisers can lead to the desire to have a more "beautiful, sculpted, or inshape body than others" (p. 325), and thus, they can exercise inappropriately in attempts of achieving it. Though not specifically measuring body image satisfaction, exercise dependence can be an indicator of body image dissatisfaction (Garner, 2002).

Brown and Fry (2013; 2014; Huddleston, Fry, \& Brown, 2012) have also measured AGPT in the physical activity domain. Studying the motivational climates perceived in various fitness arenas (i.e., national fitness franchise, aerobics classes, college recreation center), they have found that those perceiving higher caring, task-involving climates report greater commitment to exercise, positive well-being, and health-related reasons (e.g., stress relief or mobility) for exercising, as opposed to appearance-related, like tone or attractiveness (2013; 2014; Huddleston, Fry, \& Brown, 2012). Because there was a link to positive well-being and exercising for health-related reasons, and because exercising for health-related reasons is more likely to result in increased body esteem, Brown \& Fry's results seem to indicate body esteem was indirectly affected as well. 
Correspondingly, Hogue, Fry, Fry and Pressman (2013) manipulated a physical activity setting to be either caring and task-involving or ego-involving while participants were learning a new skill. Individuals in the ego-involving climate reported greater anxiety, self-consciousness, shame, and increased cortisol production during and after the session, whereas individuals in the caring and task-involving climate actually experienced a drop in cortisol production during and after the session. In addition, they reported greater enjoyment, effort, self-confidence, and interest in continuing the new skill. Experiencing anxiety, shame, and pressure found in an egoinvolving climate seems likely to worsen SPA and overall body image. Conversely, having lower cortisol production can imply less stress, so that individuals can focus on personal exercise movements instead of worry about how they look performing exercises. There seems to be a link between motivational climate and body image, but more research is needed to further define this connection.

\section{References}

Ames, C. (1992). Classrooms, goals, structures and student motivation. Journal of Educational Psychology, 84, 261-271.

Barlett, C., Harris, R., Smith, S., \& Bonds-Raacke, J. (2005). Action figures and men. Sex Roles, $53(11 / 12), 877-885$.

Battistich, V., Solomon, M., Watson, M., \& Schaps, E. (1997). Caring school communities. Educational Psychologist, 32(3), 137-152.

Brown, T.C., \& Fry, M.D. (2013). Associations between females' perceptions of college aerobic motivational climates and their responses. Women \& Health, 53 (8), 843-857.

Brown, T.C., and Fry, M.D. (2014). Motivational climate, staff and members' behaviors, and members' psychological well-being at a national fitness chain. Research Quarterly for 
Exercise and Sport, 85(2), 208-217.

Brown, T. C., Fry, M. D., \& Little, T. D. (2013). The psychometric properties of the perceived motivational climate in exercise questionnaire. Measurement in Physical Education and Exercise Science, 17(1), 22-39.

Brudzynski, L., \& Ebben, W.P. (2010). Body image as a motivator and barrier to exercise participation. International Journal of Exercise Science, 3(1), 14-24.

de Bruin, A.P., Bakker, F.C., \& Oudejans, R.R.D. (2009). Achievement goal theory and disorder eating: Relationships of disordered eating with goal orientations and motivational climate in female gymnasts and dancers. Psychology of Sport and Exercise, 10, 72-79.

Cash, T.F., \& Fleming, E. C. (2002b). The impact of body image experiences: Development of the body image quality of life inventory. The International Journal of Eating Disorders, 31(4), 455-460.

Cash, T.F., Melnyk, S.E., \& Hrabosky, J.I. (2004). The assessment of body image investment: An extensive revision of the appearance schemas inventory. The International Journal of Eating Disorders, 35(3), 305-316.

Cash, T.F., \& Pruzinsky, T. (2002) Body Image: A Handbook of Theory, Research, and Clinical Practice. New York: The Guilford Press.

Castonguay, A., Gilchirst, J., Mack, D., \& Sabiston, C. (2013). Body-related pride in young adults: An exploration of the triggers, contexts, outcomes, and attributions. Body Image, 10, $335-343$.

Clark, L., \& Tiggemann, M. (2007). Sociocultural influences and body image in 9 to 12-year-old girls: The role of appearance schemas. Journal of Clinical \& Adolescent Psychology,36(1), 76-86. 
Coppola, A.M., Ward, R.M., \& Freysinger, V.J. (2014) Coaches' Communication of Sport Body Image: Experiences of Female Athletes, Journal of Applied Sport Psychology, 26(1), 1-16.

Cox, A.E., Ullrich-French, S., Madonia, J., \&Witty, K. (2011). Social physique anxiety in physical education: Social contextual factors and links to motivation and behavior. Psychology of Sport and Exercise, 12, 555-562.

Davis, C. (2002). Body image and athleticism. In T.F. Cash \& T. Pruzinsky (Eds.) Body Image: A Handbook of Theory, Research, and Clinical Practice (219-225). New York: The Guilford Press.

Duda, J. L., \& Nicholls, J. G. (1992). Dimensions of achievement motivation in schoolwork and sport. Journal of Educational Psychology, 84(3), 290-299

Fitzsimmons-Craft, E.E., Harney, M.B., Brownstone, L.M., Higgins, M.K., Bardone-Cone, A.M. (2012). Examining social physique anxiety and disordered eating in college women. The roles of social comparison and body surveillance. Appetite, 59, 796-805.

Foreyt, J.P. (2010). Pursuit of the elusive ideal body image. Nutrition Today, 45(3), 96-97.

Fraser, S.N., \& Spink, K.S. (2002). Examining the role of social support and group cohesion in exercise compliance. Journal of Behavioral Medicine, 25 (3), 233-249.

Fry, M. D., \& Duda, J. L. (1997). Children's understanding of effort and ability in the physical and academia domains. Research Quarterly for Exercise and Sport, 68, 331-334.

Fry, M.D., \& Gano-Overway, L.A. (2010). Exploring contributions of the caring climate to the youth sport setting. Journal of Applied Sport Psychology, 22, 294-304.

Fry, M.D., Guivernau, M., Kim, M., Newton, M., Gano-Overway, L.A., \& Magyar, T.M. (2012). Youth perceptions of a caring climate, emotional regulation, and psychological wellbeing. Sport, Exercise, and Performance Psychology, 1, 44-57. 
Garner, D.M., (2002). Body image and anorexia nervosa. . In T.F. Cash \& T. Pruzinsky (Eds.) Body Image: A Handbook of Theory, Research, and Clinical Practice (295-303). New York: The Guilford Press.

Gillen, M.M., \& Lefkowitz, E.S. (2006). Gender role development and body image among male and female first year college students. Sex Roles, 55, 22-37.

González-Cutre, D., \& Sicilia, Á. (2012). Motivation and exercise dependence: A study based on self-determination theory. Research Quarterly for Exercise and Sport, 83(2), 318-329.

Goodman, N. (2011). What "Fat Talk" does for your body image. Retrieved from http://www.huffingtonpost.com/2011/08/19/fat-talk_n_927385.html on November 1, 2014.

Hagger, M.S., Hein, V., \& Chatzisarantis, N.L.D. (2011). Achievement goals, physical selfconcept, and social physique anxiety in a physical activity context. Journal of Applied Social Psychology, 41(6), 1299-1339.

Hart, E. H., Leary, M. R., \& Rejeski, W. J. (1989). The measurement of social physique anxiety. Journal of Sport \& Exercise Psychology, 11, 94-104.

Hausenblas, H.A., \& Fallon, E.A. (2006). Exercise and body image: A meta-analysis. Psychology and Health, 21 (1), 33-47.

Henriques, G.R., \& Calhoun, L.G. (1999). Gender and ethnic differences in the relationship between body esteem and self-esteem. The Journal of Psychology, 133 (4), 357-368.

Hogue, C.M., Fry, M.D., Fry, A.C., \& Pressman, S.D. (2013). The influence of a motivational climate intervention on participants' salivary cortisol and psychological responses. Journal of Sport \& Exercise Psychology, 35, 85-97.

Hubbard, S.T., Gray, J.J., \& Parker, S. (1998). Differences among women who exercise for "food related" and "non-food related" reasons. European Eating Disorders Review, 6, 255- 
265.

Huddleston, H., Fry, M.D., \& Brown, T.C. (2012). Corporate fitness members' perceptions of the environment and their intrinsic motivation. Revista de Psicolgogia del Deporte, 21 (1), 15-23.

Jaakkola, T., \& Liukkonen, J. (2006). Changes in students' self-determined motivation and goal orientation as a result of motivational climate intervention within high school physical education classes. International Journal of Sport and Exercise Psychology, 4, 302-324.

Jonsdottir, S. R., Arnarson, E. O., \& Smari, J. (2008). Body esteem, perceived competence, and depression in Icelandic adolescents. Nordic Psychology, 60(1), 58-71.

Keating, X.D., Guan, J., Piñero, J.C., \& Bridges, D.M. (2005). A meta-analysis of college students' physical activity behaviors. Journal of American College Health, 54 (2), 116-125

Koff, E., Benavage, A., \& Wong, B. (2001). Body-image attitudes and psychosocial functioning in Euro-American and Asian-American college women. Psychological Reports, 88, 917-928.

Krane, V., Greenleaf, C.A., \& Snow, J. (1997). Reaching for gold and the price of glory: A motivational case study of an elite gymnast. The Sport Psychologist, 11, 53-71.

Krane, V., Stiles-Shipley, J.A., Waldron, J., \& Michalenok, J. (2001). Relationship among body satisfaction, social physique anxiety, and eating behaviors in female athletes and exercisers. Journal of Sport Behavior, 24(3), 247-264.

Krauss Whitbourne, S., \& Skultety, K.M. (2002). Body image development: Adulthood and aging. In T.F. Cash \& T. Pruzinsky (Eds.) Body Image: A Handbook of Theory, Research, and Clinical Practice (83-90). New York: The Guilford Press.

Krueger, D.W. (2002) Psychodynamic perspectives on body image. In T.F. Cash \& T. Pruzinsky (Eds.) Body Image: A Handbook of Theory, Research, and Clinical Practice (30-37). New 
York: The Guilford Press.

Kulavic, K., Hultquist, C.N., \& McLester, J.R. (2013). A comparison of motivational factors and barriers among traditional versus nontraditional college students. Journal of American College Health, 61 (2), 60-66.

Larson, A. (2006). Student Perception of Caring Teaching in Physical Education. Sport, Education and Society, 11(4), 337-352.

Levine, M.P. \& Smolak, L. (2002). Body image development in adolescence. In T.F. Cash \& T. Pruzinsky (Eds.) Body Image: A Handbook of Theory, Research, and Clinical Practice (7482). New York: The Guilford Press.

Martin Ginis, K.A. \& Leary, M.R. (2004). Self-presentational processes in health-damaging behavior. Journal of Applied Sport Psychology, 16, 59-74.

Mccabe, M.P., Ricciardelli, L.A., \& Salmon, J. (2006). Evaluation of a prevention program to address body focus and negative affect among children. Journal of Health Psychology, 11, 589-598.

Mendelson, B.K., Mendelson, M.J., \& White, D. R. (2001). Body-esteem scale for adolescents and adults. Journal of Personality Assessment, 76(1), 90-106.

Moore, E.W.G., \& Fry, M.D. (2014). Psychometric support for the ownership in exercise and empowerment in exercise scales. Measurement in Physical Education and Exercise Science, 18(2), 135-151.

Nelson, M.C., Kocos, R., Lytle, L.A., \& Perry, C.L. (2009). Understanding perceived determinants of weight-related behaviors in late adolescence: A qualitative analysis among college youth. Journal of Nutrition Education and Behavior, 41 (4), 287-292.

Newton, M., Watson, D. L., Gano-Overway, L., Fry, M., Kim, M., \& Magyar, M. (2007). The 
role of a caring-based intervention in a physical activity setting. The Urban Review, 39(3), 281-299.

Nicholls, J.G. (1984) Achievement motivation: Concepts of ability, subjective experience, task choice and performance. Psychological Review, 91, 328-348.

Nicholls, J.G. (1989). The competitive ethos and democratic education. Cambridge, MA: Harvard University Press.

Nichter, M. (2000). Fat talk: What girls and their parents say about dieting. Cambridge, MA: Harvard University Press.

Noddings, N. (2005). The challenge to care in schools. New York, NY: Teachers College Press.

Noddings, N. (2012). The caring relation in teaching. Oxford Review of Education, 38 (6), 771781.

Olivardia, R. (2002). Body image and muscularity. In T.F. Cash \& T. Pruzinsky (Eds.) Body Image: A Handbook of Theory, Research, and Clinical Practice (210-218). New York: The Guilford Press.

Paap, C.E., \& Gardner, R.M. (2011). Body image disturbance and relationship satisfaction among college students. Personality and Individual Differences, 51, 715-719.

Petherick, C.M., \& Markland, D. (2008). The development of a goal orientation in exercise measure (GOEM), Measurement in Physical Education and Exercise Science, 12, 55-71.

President's Council on Fitness, Sports, and Nutrition. (2014). Facts \& statistics: Physical activity. Retrieved from http://www.fitness.gov/resource-center/facts-and-statistics/ on November 1, 2014.

Reinboth, M., \& Duda, J. L. (2006). Perceived motivational climate, need satisfaction, and indices of well-being in team sports: A longitudinal perspective. Psychology of Sport and 
Exercise, 7, 269-286.

Roberts, G.C. (2012). Motivation in sport and exercise from an achievement goal theory perspective: After 30 years, where are we?. In G.C. Roberts \& D.C. Treasure (Eds.), Advances in Motivation in Sport and Exercise (5-58). Champaign: Human Kinectics.

Salk, R.H., and Engeln-Maddox, E. (2011). "If you're fat, then I'm humongous!": Frequency, content, and impact of fat talk among college women. Psychology of Women Quarterly, 35, $18-28$.

Sides-Moore, L., \& Tochkov, K. (2011). The thinner the better? Competitiveness, depression, and body image among college student women. College Student Journal, 45(2), 439-448.

Sheldon, P. (2010). Pressure to be perfect: Influences on college students' body esteem. Southern Communication Journal, 75 (3), 277-298.

Smith-Jackson, T., \& Reel, J.J. (2012). Freshmen women and the "Freshman 15": Perspectives on prevalence and causes of college weight gain. Journal of American College Health, 60(1), $14-20$.

Smolak, L. (2002). Body image development in children. In T.F. Cash \& T. Pruzinsky (Eds.) Body Image: A Handbook of Theory, Research, and Clinical Practice (65-73). New York: The Guilford Press.

Smolak, L. (2004). Body image in children and adolescents: Where do we go from here? Body Image, 1, 15-28.

Stark, A., \& Newton, M. (2014). A dancer's well-being: The influence of the social psychological climate during adolescence. Psychology of Sport and Exercise, 15, 356-363.

Sylvia, Z., King, T.K, Morse, B.J. (2014) Virtual ideals: The effect of video game play on male body image. Computers in Human Behavior, 37, 183-188. 
Tiggemann, M. (2001). The impact of adolescent girls' life concerns and leisure activities on body dissatisfaction, disordered eating, and self-esteem. The Journal of Genetic Psychology, 162(2), 133-142.

Tiggemann, M. (2002). Media influences on body image development. In T.F. Cash \& T. Pruzinsky (Eds.) Body Image: A Handbook of Theory, Research, and Clinical Practice (9198). New York: The Guilford Press

Tiggemann, M., \& Williamson, S. (2000). The effect of exercise on body satisfaction and selfesteem as a function of gender and age. Sex Roles, 43, 119-127.

Thompson, J. K., Heinberg, L. J., Altabe, M., \& Tantleff-Dunn, S. (1999). Exacting beauty: Theory, assessment, and treatment of body image disturbance. Washington, DC: American Psychological Association.

Vander Wal, J.S., \& Thelen, M.H. (2000). Predictors of body image dissatisfaction in elementary-age school girls. Eating Behaviors, 1, 105-122

Vella-Zarb, R.A., \& Elgar, F.J. (2010). Predicting the "freshman 15": Environmental and psychological predictors of weight gain in first-year university students. Health Education Journal, 69(3), 321-332.

Waldron, J.J., \& Krane, V. (2005). Whatever it takes: Health compromising behaviors in female athletes. Quest, 57, 315-329.

Whitbourne, S. K., \& Skultety, K.M. (2002). Body image development: Adulthood and aging. In T.F. Cash \& T. Pruzinsky (Eds.) Body Image: A Handbook of Theory, Research, and Clinical Practice (65-73). New York: The Guilford Press.

World Health Organization [WHO]. (2014). 10 Facts on Physical Activity. Retrieved from http://www.who.int/features/factfiles/physical_activity/facts/en/ on November 17. 


\section{Appendix C:}

\section{SCALES AND QUESTIONNAIRES}

Body Esteem Scale for Adults and Adolescents: Weight, Appearance; Abbreviated Perceived Motivational Climate in Exercise Questionnaire; Caring Climate Scale; Social Physique Anxiety Scale; Demographic and Descriptive Information 


\begin{tabular}{|c|c|c|c|c|c|}
\hline $\begin{array}{l}\text { Body Esteem Scale for Adolescents and Adults: Appearance } \\
\text { and Weight (BESAA; Mendelson, Mendelson, \& White, 2001; } \\
\text { Appearance subscale items italicized) } \\
\text { Directions: Read each statement and think about how much } \\
\text { you believe the statement is characteristic of you. Then } \\
\text { choose the answer that indicates how often the statement is } \\
\text { true of you. }\end{array}$ & ষ্ঠ & 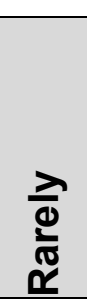 & 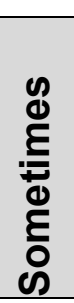 & क्ष̃ & $\frac{\infty}{\frac{\pi}{3}}$ \\
\hline $\begin{array}{l}\text { 1. There are a lot of things I would change about my } \\
\text { looks if I could. }\end{array}$ & 0 & 1 & 2 & 3 & 4 \\
\hline 2. I wish I looked better. & 0 & 1 & 2 & 3 & 4 \\
\hline 3. I think I have a good body. & 0 & 1 & 2 & 3 & 4 \\
\hline 4. I worry about the way I look. & 0 & 1 & 2 & 3 & 4 \\
\hline 5. I like what I look like in pictures. & 0 & 1 & 2 & 3 & 4 \\
\hline 6. My looks upset me. & 0 & 1 & 2 & 3 & 4 \\
\hline 7. I am pretty happy about the way I look. & 0 & 1 & 2 & 3 & 4 \\
\hline 8. I am proud of my body. & 0 & 1 & 2 & 3 & 4 \\
\hline 9. I am looking as nice as I would like to. & 0 & 1 & 2 & 3 & 4 \\
\hline 10. I feel ashamed of how I look. & 0 & 1 & 2 & 3 & 4 \\
\hline 11. I am satisfied with my weight. & 0 & 1 & 2 & 3 & 4 \\
\hline 12. I like what I see when I look in the mirror. & 0 & 1 & 2 & 3 & 4 \\
\hline 13. Weighing myself depresses me. & 0 & 1 & 2 & 3 & 4 \\
\hline 14. I feel I weigh the right amount for my height. & 0 & 1 & 2 & 3 & 4 \\
\hline $\begin{array}{l}\text { 15. I am preoccupied with trying to change my body } \\
\text { weight. }\end{array}$ & 0 & 1 & 2 & 3 & 4 \\
\hline 16. My weight makes me happy. & 0 & 1 & 2 & 3 & 4 \\
\hline 17. I wish I looked like someone else. & 0 & 1 & 2 & 3 & 4 \\
\hline 18. I really like what I weigh. & 0 & 1 & 2 & 3 & 4 \\
\hline
\end{tabular}




\begin{tabular}{|c|c|c|c|c|c|}
\hline $\begin{array}{l}\text { Perceived Motivational Climate in Exercise Questionnaire- } \\
\text { Short (PMCEQ-Short; Moore, Brown, \& Fry, under review. Ego } \\
\text { items italicized). } \\
\text { Directions: Read each statement and think about how much } \\
\text { you believe the statement describes the environment within } \\
\text { your class. Then choose the answer that shows how much } \\
\text { you agree or disagree with each statement. }\end{array}$ & 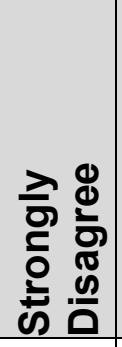 & 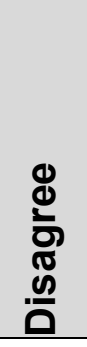 & 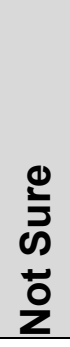 & ֻँ & 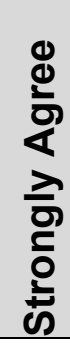 \\
\hline $\begin{array}{l}\text { 1. In this class, students of all fitness levels are made } \\
\text { to feel valued. }\end{array}$ & 1 & 2 & 3 & 4 & 5 \\
\hline $\begin{array}{l}\text { 2. In this class, students are rewarded and noticed } \\
\text { when they try hard. }\end{array}$ & 1 & 2 & 3 & 4 & 5 \\
\hline $\begin{array}{l}\text { 3. In this class, students are embarrassed if they don't } \\
\text { know how to use the equipment or perform an } \\
\text { exercise/skill/drill. }\end{array}$ & 1 & 2 & 3 & 4 & 5 \\
\hline $\begin{array}{l}\text { 4. In this class, the instructor encourages students to } \\
\text { try new skills. }\end{array}$ & 1 & 2 & 3 & 4 & 5 \\
\hline $\begin{array}{l}\text { 5. In this class, students are encouraged to do better } \\
\text { than other students. }\end{array}$ & 1 & 2 & 3 & 4 & 5 \\
\hline $\begin{array}{l}\text { 6. In this class, students are hesitant/embarrassed to } \\
\text { ask the instructor questions. }\end{array}$ & 1 & 2 & 3 & 4 & 5 \\
\hline $\begin{array}{l}\text { 7. In this class, the instructor encourages students to } \\
\text { help each other. }\end{array}$ & 1 & 2 & 3 & 4 & 5 \\
\hline $\begin{array}{l}\text { 8. In this class, the instructor makes it clear who he/she } \\
\text { thinks are the most fit or skilled students. }\end{array}$ & 1 & 2 & 3 & 4 & 5 \\
\hline $\begin{array}{l}\text { 9. In this class, students are excited when they do } \\
\text { better than their fellow students. }\end{array}$ & 1 & 2 & 3 & 4 & 5 \\
\hline $\begin{array}{l}\text { 10. In this class, the instructor always emphasizes } \\
\text { trying your best. }\end{array}$ & 1 & 2 & 3 & 4 & 5 \\
\hline $\begin{array}{l}\text { 11. In this class, the instructor gives most of his/her } \\
\text { attention to only a few students. }\end{array}$ & 1 & 2 & 3 & 4 & 5 \\
\hline $\begin{array}{l}\text { 12. In this class, the focus is to keep improving each } \\
\text { exercise/skill }\end{array}$ & 1 & 2 & 3 & 4 & 5 \\
\hline
\end{tabular}




\section{Caring Climate Scale (CCS; Newton, Watson, Gano-Overway, Fry, Kim, \& Magyar, 2007). \\ Directions: Read each statement and think about how much you believe the statement describes the environment within your class. Then choose the answer that shows how much you agree or disagree with each statement.}
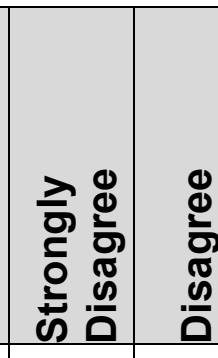

1. In this class, students are treated with respect.

2. In this class, the instructor respects students.

3. In this class, the instructor is kind to students.

(1)

1

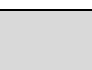

1

\begin{tabular}{l}
\hline 4. In this class, the instructor cares about students. \\
\hline 5. In this class, students feel that they are treated fairly. \\
\hline 6. In this class, the instructor tries to help students. \\
\hline $\begin{array}{l}\text { 7. In this class, the instructor wants to get to know all } \\
\text { the students. }\end{array}$
\end{tabular}
8. In this class, the instructor listens to students.
9. In this class, students like one another for who they are.

10. In this class, the instructor accepts students for who they are.

11. In this class, students feel comfortable.

12. In this class, students feel safe.

13. In this class, students feel welcome.

1

1

1

2

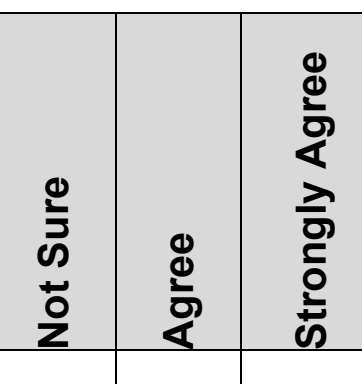

\begin{tabular}{|l|l|l|l|}
2 & 3 & 4 & 5 \\
\hline
\end{tabular}

\begin{tabular}{|l|l|l|l|l|}
1 & 2 & 3 & 4 & 5 \\
\hline
\end{tabular}

\begin{tabular}{|l|l|l|l|l|}
\hline 1 & 2 & 3 & 4 & 5 \\
\hline 1 & 2 & 3 & 4 & 5 \\
\hline
\end{tabular}

\begin{tabular}{|l|l|l|l|l|}
\hline 1 & 2 & 3 & 4 & 5 \\
\hline 1 & 2 & 3 & 4 & 5 \\
\hline
\end{tabular}

\begin{tabular}{|l|l|l|l|l|}
\hline 1 & 2 & 3 & 4 & 5 \\
\hline 1 & 2 & 3 & 4 & 5 \\
\hline 1 & 2 & 3 & 4 & 5 \\
\hline
\end{tabular}

\begin{tabular}{|l|l|l|l|l|}
\hline 1 & 2 & 3 & 4 & 5 \\
\hline 1 & 2 & 3 & 4 & 5 \\
\hline 1 & 2 & 3 & 4 & 5 \\
\hline 1 & 2 & 3 & 4 & 5 \\
\hline 1 & 2 & 3 & 4 & 5 \\
\hline
\end{tabular}




\begin{tabular}{|c|c|c|c|c|c|}
\hline $\begin{array}{l}\text { Social Physique Anxiety Scale (SPAS; Heart, Leary, \& } \\
\text { Rejeski, 1989) adapted for this study. } \\
\text { Directions: Read each statement and think about how much } \\
\text { you believe the statement is true of you during this class. } \\
\text { Then choose the answer that indicates how much the } \\
\text { statement is characteristic of you during this class. }\end{array}$ & 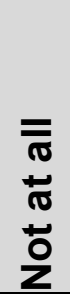 & $\begin{array}{l}\vec{\lambda} \\
\frac{\vec{t}}{0} \\
\frac{0}{\omega}\end{array}$ & $\begin{array}{l}\frac{\lambda}{0} \\
\frac{\pi}{\pi} \\
\frac{0}{0} \\
\frac{0}{0} \\
\sum\end{array}$ & $\sum_{j}^{\frac{\pi}{0}}$ & 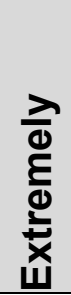 \\
\hline $\begin{array}{l}\text { 1. In this class, I am comfortable with the appearance } \\
\text { of my physique/figure. }\end{array}$ & 1 & 2 & 3 & 4 & 5 \\
\hline $\begin{array}{l}\text { 2. In this class, I worry about wearing clothes that might } \\
\text { make me look too thin or overweight. }\end{array}$ & 1 & 2 & 3 & 4 & 5 \\
\hline $\begin{array}{l}\text { 3. In this class, I wish I wasn't so uptight about my } \\
\text { physique/figure. }\end{array}$ & 1 & 2 & 3 & 4 & 5 \\
\hline $\begin{array}{l}\text { 4. In this class, there are times when I am bothered by } \\
\text { thoughts that other people are evaluating my weight or } \\
\text { muscular development negatively. }\end{array}$ & 1 & 2 & 3 & 4 & 5 \\
\hline $\begin{array}{l}\text { 5. In this class, when I look in the mirror, I feel good } \\
\text { about my physique/figure. }\end{array}$ & 1 & 2 & 3 & 4 & 5 \\
\hline $\begin{array}{l}\text { 6. In this class, unattractive features of my } \\
\text { physique/figure make me nervous. }\end{array}$ & 1 & 2 & 3 & 4 & 5 \\
\hline $\begin{array}{l}\text { 7. In this class, I feel apprehensive about my } \\
\text { physique/figure. }\end{array}$ & 1 & 2 & 3 & 4 & 5 \\
\hline $\begin{array}{l}\text { 8. In this class, I am comfortable with how fit my body } \\
\text { appears to others. }\end{array}$ & 1 & 2 & 3 & 4 & 5 \\
\hline $\begin{array}{l}\text { 9. In this class, it would make me uncomfortable to } \\
\text { know others were evaluating my physique/figure. }\end{array}$ & 1 & 2 & 3 & 4 & 5 \\
\hline $\begin{array}{l}\text { 10. In this class, when it comes to displaying my } \\
\text { physique/figure to others, I am a shy person. }\end{array}$ & 1 & 2 & 3 & 4 & 5 \\
\hline $\begin{array}{l}\text { 11. In this class, I usually feel relaxed when it is } \\
\text { obvious that others are looking at my physique/figure. }\end{array}$ & 1 & 2 & 3 & 4 & 5 \\
\hline
\end{tabular}




\section{Please answer the following questions:}

1. Are you currently trying to lose weight? (please circle either yes or no)
Yes
No

2. Are you currently trying to gain weight? (please circle either yes or no)

Yes No

3. I identify my gender as. . ( (please check only one)
[ ] Man
[ ] Woman
[ ] Trans*
[ ] (please fill in the blank)

4. Please indicate your age. . . years (please fill in the blank)

5. Please indicate your ethnicity by circling a response below:

Caucasian/White

African American/Black

Hispanic Latino
Native American

Asian/Pacific Island

Other

6. In total, how many HSES 108 activities courses have you taken? Please include this semester.

$$
\text { class(es) }
$$

7. About how many days of the week do you engage in physical activity outside of this class period? (please circle an answer below)
0 days
1-2 days
3-4 days
5-7 days 
8. What is your current year in school? (please circle an answer below)

Freshman Sophomore Junior Senior Graduate Student

9. Did you take this class because of the instructor? (Please circle either yes or no)

Yes No

10. Have you had this instructor in previous classes? (Please circle either yes or no)

Yes

No 